\title{
Abstracts
}

3rd Sechenov International Biomedical Summit (SIBS 2019), Moscow, May 20-21, 2019

\section{Organizing and Program Committee}

Chairman of the Organizing Committee:

Petr Glybochko, Moscow

Co-Chair of the Organizing Committee:

Valerian E. Kagan, Moscow

Vice-Chairmen of the Organizing Committee:

Andrey A. Svistunov, Moscow

Denis V. Butnaru, Moscow

Members of the Organizing Committee:

Olga S. Sadkovaya, Moscow

Peter S. Timashev, Moscow

Filipp Yu. Kopylov, Moscow

Vadim V. Tarasov, Moscow

Tatyana M. Zharikova, Moscow

Dmitry V. Telyshev, Moscow 
S. Karger

Medical and Scientific Publishers

Basel · Freiburg $\cdot$ Hartford $\cdot$ Oxford Bangkok $\cdot$ Dubai $\cdot$ Kuala Lumpur .

Melbourne $\cdot$ Mexico City

Moscow $\cdot$ New Delhi $\cdot$ Paris ·

Shanghai $\cdot$ Tokyo

www.karger.com
Disclaimer

The statements, opinions and data contained in this publication are solely those of the individua authors and contributors and not of the publish er and the editor(s). The appearance of advertise ments in the journal is not a warranty, endorsement, or approval of the products or service advertised or of their effectiveness, quality or safety. The publisher and the editor(s) disclaim responsibility for any injury to persons or property resulting from any ideas, methods, instructions or products referred to in the content or ad vertisements.

Drug Dosage

The authors and the publisher have exerted every effort to ensure that drug selection and dosage set forth in this text are in accord with current recommendations and practice at the time of publication. However, in view of ongoing research, changes in government regulations, and the constant flow of information relating to drug therap and drug reactions, the reader is urged to check the package insert for each drug for any change in indications and dosage and for added warnings and precautions. This is particularly important when the recommended agent is a new and/ or infrequently employed drug.
All rights reserved.

No part of this publication may be translated into other languages, reproduced or utilized in any form or by any means, electronic or mechanical including photocopying, recording, microcopying, or by any information storage and retrieval system, without permission in writing from the publisher or, in the case of photocopying, direct payment of a specified fee to the Copyright Clearance Center (see ‘General Information’).

(c) Copyright 2019 by S. Karger AG,

P.O. Box, CH-4009 Basel (Switzerland) 


\section{Bio-Engineering and Regenerative Medicine}

THE INHIBITORY EFFECT OF POLYPHENOLS ON THE PROCESS OF LIPID PEROXIDATION

Babenkova I.V. ${ }^{1}$, Buravlev E.A. ${ }^{1,2}$, Teselkin Yu.O. ${ }^{1}$

${ }^{1}$ Pirogov Russian National Research Medical University, Moscow, Russia

${ }^{2}$ I.M. Sechenov First Moscow State Medical University (Sechenov University), Moscow, Russia

teselkin-box@mail.ru

Objective. One of the mechanisms of antioxidant action of dihydroquercetin in vivo is believed to be its ability to protect biological membranes from the process of lipid peroxidation. In our opinion, the antioxidant activity of dihydroquercetin in these model systems is due to its interaction with lipid radicals. At the same time, it was established that dihydroquercetin interacts with $\mathrm{Fe}^{2+}$ ions to form a catalytically inactive complex. The dihydroquercetin chelating activity may be no less important component of its antioxidant activity, since $\mathrm{Fe}^{2+}$ ions play an important role in initiating the lipid peroxidation process of biological membranes in vivo. Thus, it remains unclear which of the mechanisms of antioxidant action of dihydroquercetin is the determining factor in the protection of membranes from the lipid peroxidation process.

Methods. A convenient model for studying of the membrane-protective effect of biologically active substances are liposomes. Membrane protective effect of dihydroquercetin, rutin and fellamurin has been studied using the model of $\mathrm{Fe}^{2+}$-induced free radical oxidation of liposomes from egg phospholipids.

Results. The antioxidative activity of dihydroquercetin was estimated by measuring of liposome chemiluminescence and accumulation of malonic dialdehyde(MDA) in reactive mixture. It was shown that the dihydroquercetin decreased chemiluminescence intensity, increased the time to maximum chemiluminescence and reduced MDA accumulation similar to lipophil chain-breaking radical inhibitor - $\alpha$-tocopherol and butylated hydroxytoluene.

Conclusion. It was concluded that mechanism of antioxidative effect of dihydroquercetin in $\mathrm{Fe}^{2+}$-liposomes system consists in scavenging of lipid radicals. Membrane protective effect of dihydroquercetin was more high in comparison with two another investigated flavonoids - rutin and fellamurin.

\section{2 \\ CREATION OF AN INJECTABLE TISSUE-SPECIFIC MATRIX FROM DECELLULARIZED FRAGMENTS OF ARTICULAR CARTILAGE}

Basok Yu. B., Kirillova A.D., Grigoryev A. M., Kuznetsova E.G., Kirsanova L.A. , Nemets E.A.

Academician V.I.Shumakov Federal Research Center of Transplantology and Artificial Organs, Moscow, Russia bjb2005@mail.ru

Tissue decellularization allows cells destruction and gene material removal while maintaining the structure of tissue-specific extracellular matrix (ECM). Micronization of the articular cartilage fragments does not only provide for the complete decellularization, but also increases the area of cell settlement and allows the injection administration of tissue-engineered constructs.

Purpose. Obtaining an injectable form of microdispersed tissue-specific matrix from decellularized porcine articular cartilage.

Materials and methods. Micronization of cartilage tissue was carried out in CryoMill (Retch GmBH, Germany). The particle size was determined by the method of sedimentation on the analyzer of dispersion LUMiSizer (LUM, Germany) in infrared light $(865 \mathrm{~nm})$ at $25^{\circ}$ C. For sample decellularization a combination 
of freezing/thawing processes (-196을 $\left.\mathrm{C} 37^{\circ} \mathrm{C} \mathrm{C}\right)$ with the treatment of surface-active substances (surfactant) - sodium dodecyl sulfate, Triton X-100 and DNase was used. The morphology of the matrix was assessed histologically. DNA was isolated using the DNeasy Blood \& Tissue Kit (QIAGEN, Germany). The effectiveness of surfactant washing was assessed by the cytotoxicity of the matrix on cultures of mouse fibroblasts L929 and human adipose tissue mesenchymal stromal cells (hADSCs). To assess the hemocompatibility of the samples obtained, their hemolytic activity was studied in vitro.

Results. The range of sizes of the cartilage microparticles obtained demonstrates the possibility of their injection administration $(<220 \mu \mathrm{m})$. The combination of stages, including 3 cycles of freezing/thawing, followed by treatment with surfactant solutions and DNase, allowed to achieve the complete absence of nondecellularized microparticles with a residual DNA content of $9.11 \pm 1.13 \mathrm{ng} / \mathrm{mg}$ of tissue. The matrix did not possess hemolytic activity and cytotoxicity on mouse fibroblasts L929 and hADSCs.

Conclusion. The method for producing an injectable form of microdispersed tissue-specific matrix from decellularized porcine articular cartilage was developed.

The reported study was funded partially by RFBR according to the research project № 18-29-06012.

\section{3}

\section{BIMATERIAL TECHNIQUE FOR CREATION OF MULTILAYER TISSUE SCAFFOLDS}

Beketov E.E. ${ }^{*}$, Isaeva E.V. ${ }^{1}$, Nasedkina N.V. ${ }^{1}$, Kisel A.A. ${ }^{1}$, Shegay P.V. ${ }^{2}$, Ivanov S.A. ${ }^{1}$, Kaprin A.D. ${ }^{2}$

${ }^{1}$ A. Tsyb Medical Radiological Research Center - branch of the National Medical Research Radiological

Center of the Ministry of Health of the Russian Federation, Obninsk, Russia

${ }^{2}$ National Medical Research Radiological Center of the Ministry of Health of the Russian Federation,

Obninsk, Russia

beketov.ee@yandex.ru

It is known that even the simplest human tissues are well-organized, multilayered structures. Thus the use of only multilayer pattern of tissue scaffold is a proper choice. One of the solutions in case of middle price category bioprinters, with no more than two print heads (both - biodispenser) the use of pre-fabricated frame of stable (GelMA) and sacrificial (gelatin) biomaterial with subsequent filling the holes with cell-laden hydrogel. At the moment, the team of authors is developing the approach.

As an illustrative model the following scaffold pattern can be considered: $12 \times 30 \mathrm{~mm}$ area structure with $4 \mathrm{~mm}$ height. These dimensions are appropriate for $3.5 \mathrm{~cm}$ Petri dishes for further scaffold maturation. The structure provides three layers of $10 \times 10 \mathrm{~mm}$ working area for cellular component. The design of the scaffold includes the base of GelMA, gelatin layers with GelMA borders, GelMA layers separating the gelatin layers and the top layer of GelMA. After manufacturing or immediately before implantation into an organism the scaffold can be cut to the boundaries of the working area, and $10 \times 10 \times 4 \mathrm{~mm}$ structure of will be formed.

The main advantage of the proposed approach is independence from the number of printer dispensers. The use of only two materials with appropriate nozzle selection makes it possible to achieve up to 5 cell-laden layers for $4 \mathrm{~mm}$ scaffold. The development of the approach continues.

\section{4}

\section{AUTOLOGOUS REGENERATIVE CELLS OF ADIPOSE TISSUE ARE USED IN THE TREATMENT OF LARGE JOINT OSTEOARTHROSIS}

Berdugina O.V. ${ }^{1}$, Borzunov I.V. ${ }^{1}$, Berdugin K.A. ${ }^{1,2}$, Shlykov I.L. ${ }^{1,2}$

${ }^{1}$ Ural state medical university

${ }^{2}$ Ural Institute of Traumatology and Orthopaedics name of V.D.Chaklin, Ekaterinburg, Russia

berolga73@rambler.ru

According to the World Health Organization, large joint osteoarthrosis opens the second decade ranking of diseases that cause disability.

The aim of the study was the development of new technology of conservative treatment of large joint osteoarthrosis using autologous regenerative cells in adipose tissue. 
A study performed by receiving autologous adipose tissue in compliance with rules of aseptic and antiseptics. Autologous cells extracted by enzymatic treatment an equal volume of sample solution collagenase type 2 (Sigma, USA). Then remove the enzyme was conducted applying Hartman's solution. Certification of samples carried out in accordance with the standard operating procedure, which included mandatory determination of total number of selected cells using hematology cell counter, definition of cell viability by coloring them trypan blue, as well as establishing the composition of the flow cytometry method, the subpopulation on the BD FACS Canto II (Becton Dickinson, USA). Detection of cell products carried out after dyeing their antibodies, labeled staining (reagents company Becton Dickinson, USA) in accordance with the manufacturer's instructions. Researched surface markers CD3, CD4, CD14, CD31, CD34, CD45, CD90, CD105, and CD146. Intra-articular introduction cells carried out under local anesthesia in a prone position with aseptic and fixing bandages. Monitoring of undesirable complications included clinical, instrumental and laboratory studies (clinical, biochemical, immunological) questionnaire on the scale of assessment of the quality of life of the Short Form-3 (SF-36), the scale of assessment of the state of the knee joint Knee and Osteoarthritis Outcome Score (KOOS), questionnaire on the Visual and Analog Scale (VAS), questionnaire Knee Scoring Scale (KSS).

It is established that the application of the proposed method enables to effectively reduce persistent pain in the joint. The application of the proposed technologies in a broad network of specialized orthopedic offices and clinics will significantly improve the results of treatment. It is possible to use in monotherapy and in combination treatment.

\section{5}

\section{BIOMARKERS OF BONE TISSUE REGENERATION IN THE DAMAGED SPINE}

Berdugina O.V. ${ }^{1}$, Berdugin K.A. ${ }^{1,2}$

${ }^{1}$ Ural state medical university,

${ }^{2}$ Ural Institute of Traumatology and Orthopaedics name of V.D.Chaklin, Ekaterinburg, Russia

berolga73@rambler.ru

General clinical and biochemical laboratory tests do not allow you to evaluate the nature of regeneration of bone tissue. Radiological assessment of the seam can be performed not earlier than one month after the start of the regeneration.

The aim of the study was to establish immunological markers for assessing and forecasting the nature of regeneration of bone tissue in surgical treatment of spinal injuries.

Blood examination in 111 patients with uncomplicated fractures of the spine. Based on clinical and radiological retrospective analysis, the patients were divided into groups with normal bone consolidation, with delayed consolidation of bone tissue and incomplete formation of bone block stimulus for the segment. Immunological analysis of peripheral blood included: phenotypic evaluation of cells defining, functionalmetabolic activity of phagocytes, establishing levels of immunoglobulins, cytokines concentrations and their soluble receptors - IL-1 $\alpha$, Il-1 $\beta$, IL-1ra and IL-8, TNF- $\alpha$. Acute phase reaction was assessed by altering the concentration of C-reactive protein, fibrinogen, gaptoglobin, ceruloplasmin. The results were processed statistically using the program «Statistica» (StatSoft, USA) ver. 6.0.

In patients with delayed consolidation of bone tissue before surgery has decreased the number of monocytes, level of IgM and IgG. In the postoperative period identified changing the number of CD3 ${ }^{+}-, \mathrm{CD}_{19}{ }^{+}$-cells, reducing the concentration of CRP, IgA and IgG, increasing the concentration of fibrinogen, gaptoglobin, IgM. In patients with incomplete formation of bone block after the operation decreasing the number of phagocytes is present in $40,0 \%(p<0.05)$, monocytes - in $23,3 \%(p<0.05)$ and eosinophils - in $31,2 \%(p<0.05)$, the number of CD19+-cells, IgA, IgM.

There is reason to believe that a deviation from the normal regeneration of bone tissue due to lower immune reactivity. 


\title{
6
}

\section{BIOLOGICAL INDICATORS OF THE BONE FORMING VIOLATIONS WHEN DAMAGED, IF THERE IS A NONSPECIFIC OSTEOMYELITIS}

\author{
Berdugina O.V. ${ }^{1}$, Berdugin K.A. ${ }^{1,2}$ \\ ${ }^{1}$ Ural state medical university, \\ ${ }^{2}$ Ural Institute of Traumatology and Orthopaedics name of V.D.Chaklin, Ekaterinburg, Russia \\ berolga73@rambler.ru
}

The presence of nonspecific osteomyelitis with bone forming makes it difficult to assess the damage.

The aim of the study was finding the laboratory criteria of the bone forming violations if the damage is in the midst of nonspecific osteomyelitis.

Surveyed 382 patients with damage bone, of which 136 - broken mandible, 27 - damaged long tube bones, 111 - spine, 108 - hip and femur bones. Studied cellular immunity, humoral responses of blood, standard markers of inflammation, response of phagocytes and cytokines.

It has been established that a violation of the bone forming at osteomielite accompanied by leukocytosis, reduced number of $\mathrm{CD} 19^{+}$- and $\mathrm{CD}^{+}$-cells (the last cells decreased 40.8\%), decreasing levels of lactoferrin. At the same time, increasing phagocytic activity of neutrophils, activation of the systemic inflammatory reactions. This is known according to the dynamics of reacting slowly to the acute-phase protein - ceruloplasmin. Violation of the bone forming the conditions of osteomyelitis is accompanied by a change in the relationship between the levels of IL-1 $\alpha$ and IL-1ra after reconstructive surgery. While in patients with normal bone consolidation in osteomyelitis and osteomyelitis without equal ratio, while delayed bone formation IL-1ra level almost in 2 times lower concentrations of IL- $1 \alpha$. In the synthesis of collagen when delayed bone formation noted the decrease in the number of neutrophils and lymphocytes respectively $23 \%$ and $21 \%$, identify signs of oppression of humoral immunity (reduced values of IgA, IgM, IgG), phagocytosis (myeloperoxidase) and nonspecific resistance (lysozyme).

Biological indicators of the detainee forming bones make it possible to assess the dynamics of the process while restoring.

\section{7 \\ COMPARISON OF FIBRIN AND COLLAGEN HYDROGELS PROPERTIES IN TERMS OF TISSUE ENGINEERING}

\author{
Bikmulina P.Y. ${ }^{1}$, Kosheleva N.V. ${ }^{2,3}$, Shpichka A.I. ${ }^{1}$, Rochev Y.A. ${ }^{1,4}$ \\ ${ }^{1}$ Institute for Regenerative Medicine, Sechenov University, Moscow, Russia \\ ${ }^{2}$ Faculty of Biology, Lomonosov Moscow State University, Moscow, Russia \\ ${ }^{3}$ FSBSI Institute of General Pathology and Pathophysiology, Moscow, Russia \\ ${ }^{4}$ National University of Ireland, Galway (NUI Galway), Galway, Ireland \\ polina_bikmulina@mail.ru
}

Objective. The primary objective of tissue engineering is to create scaffolds which provide cells with conditions similar to those in vivo. Varying the parameters of scaffold is the simplest way to find such conditions. Also the scaffold should perform an ability to analyze cell state to estimate potential of using in regenerative medicine. Different hydrogels meet all these requirements. It is possible to modulate wide range of tissue-like conditions in hydrogels by changing their thickness, porosity, cell composition and density.

Methods. Two types of hydrogels inoculated with mouse embryonic fibroblasts 3T3 were chosen - fibrin (Sigma Aldrich) and collagen hydrogels in concentrations 12,5;25; 50 and 0,5; 1; 1,5 mg/ml, respectively. The thickness of hydrogel varied from 1 to $3 \mathrm{~mm}$. Alamar blue (Invitrogen) and Live-Dead (Sigma Aldrich) assays were used to study cell viability. Proliferation rates were analyzed with PicoGreen assay (Invitrogen).

Results. Investigation of the cell-free systems showed that fluorescence in collagen hydrogels decreases by $10-30 \%$ with rising of gel thickness and concentration, while these parameters do not affect transparent 
fibrin hydrogels. Increased concentration and thickness of both hydrogels reduces cell viability. Comparing the fluorescence intensity from cells in monolayer and 3D cultures revealed that hydrogels diminish fluorescence by $15 \%$ on average. This effect is associated with less active proliferation in hydrogels.

Conclusion. This study shows that hydrogels analyzed with listed tests represent successful model for studies of cell activities in 3D scaffolds.

The study was financially supported by Russian Science Foundation (grant № 15-15-00132).

\section{8 \\ COMPARATIVE EVALUATION OF THE EFFICACY OF TWO PERFUSION DECELLULARIZATION PROTOCOLS FOR OBTAINING FULLY ACELLULAR VASCULAR SCAFFOLD}

Brumberg V.A., Astrelina T.A., Nikitina V.A., Kobzeva I.V., Suchkova Yu.B., Usupzhanova D.Yu., Brunchukov V.A., Rastorgueva A.A., Karaseva T.V., Lischuk S.V., Dubova E.A., Makhova A.E., Lomonosova E.E., Dobrovolsskaya E.l., Bushmanov A.Yu., Samoilov A.S.

Burnasyan Federal Medical Biophysical Center of Federal Medical Biological Agency, Moscow, Russia brumb1225@gmail.com

Relevance. In reconstructive vascular surgery, small caliber vessels substitutes still remain an unmet clinical need. Decellularization is the complete removal of all cellular and nuclear matters from a tissue while leaving a preserved extracellular matrix representing a promising tool for the generation of acellular scaffolds for potential clinical use. However, in practice obtaining a fully acellular scaffold is very challenging since all residual chromatin and fragmented nuclei may not observable in histologic analysis but can be seen using more specific methods, like DAPI fluorescent staining. So there is a need in a quantative evaluation of decellularization efficacy. Purpose. To evaluate the extent of cell nuclei removal (\%) for two different perfusion decellularization protocols of pig aorta segments and to assess residual genomic DNA in decellularized tissue slices.

Materials and methods. Abdominal descending aorta (inner diameter of $5 \mathrm{~mm}$ ) was obtained from one pig under general anesthesia and orotracheal ventilation. Then in laminar hood the abdominal aorta was sliced for two segments each was processed further with two different perfusion decellularization protocol. Also biopsies of $0,5^{*} 0,5 \mathrm{~cm} 2$ were taken for native tissue characterization. Decellularized vascular scaffolds $(\mathrm{n}=2)$ were obtained by perfusion with enzymatic $(0.2 \mathrm{mg} / \mathrm{ml}$ of DNase I and $0.04 \mathrm{mg} / \mathrm{ml}$ of RNase), hypo-and hypertonic salt solutions in a customized tubular glass chamber placed in a flow bioreactor. Decellularization quality was evaluated by histological studies of deparaffinized and rehydrated tissue sections, immunohistochemical (IHC) reactions with primary antibodies to type I collagen and collagen IV of basal membranes. Additionally, removal of nuclear remnants and chromatin was assessed by DAPI staining of frozen tissue sections. Afterwards scaffolds were thoroughly rinsed with PBS and 0,5\% antibiotic - antimycotic solution at $37^{\circ} \mathrm{C}$ to remove residual traces of detergents.

Results. Both protocols for pig aorta decellularization lead to cell nuclei and cytoplasm removal confirmed by histologic analysis, mean porosity to be estimated as $15 \pm 2 \mu \mathrm{m}$ regardless of protocol applied. This is well coordinated with literature data regarding decellularized scaffold porosity. Both protocols lead to preservation of Col IV (4+) while Col I was partially denaturated (2+). Use of DNAse I in protocol 2 instead of $\mathrm{NH} 4 \mathrm{Cl}$ leads to elimination of cell nuclei as well as residual chromatin. Decellularization efficacy was calculated as: $\mathrm{E}=100 \%-(\mathrm{Nd} / \mathrm{Nn})$, where $\mathrm{Nd}-$ nuclei count in decellularized tissue slice, $\mathrm{Nn}$ - nuclear count for native one. For protocol I, it was equal 93, 19\% whilst for protocol II - 97\%. Agarose gel electrophoresis of DNA extracted from both tissue slices showed that residual DNA was genomic with quantity not exceeding $50 \mathrm{ng} / \mathrm{mg}$ and $40 \mathrm{ng} / \mathrm{mg}$ for protocols 1 and 2, respectively.

Conclusion. In conclusion, DAPI staining is far more sensitive method for estimation of residual chromatin then hematoxylin - eosin assay and hence its more accurate for characterization of acellular scaffold for its immunogenicity and feasibility for further recellularization. 


\section{9 \\ EXPERIMENTAL TREATMENT OF RADIATION SKIN LESIONS WITH MESENCHYMAL STEM CELLS AND THEIR CONDITIONED MEDIA}

Brunchukov V.A., Astrelina T.A., Nikitina V.A., Kobzeva I.V., Suchkova Yu.B., Usupzhanova D.Yu., Rastorgueva A.A., Karaseva T.V., Gordeev A.V., Maxsimova O.A., Lischuk S.V., Dubova E.A., Pavlov K.A., Brumberg V.A., Makhova A.E., Lomonosova E.E., Dobrovolsskaya E.I., Barabash I.M., Bushmanov A.Yu., Samoilov A.S.

Burnasyan Federal Medical Biophysical Center of Federal Medical Biological Agency, Moscow, Russia brunya2008@yandex.ru

Purpose. To study the regeneration processes in the treatment of radiation skin lesions with the mesenchymal stem cells (MSC) derived from human gingiva and their conditional medium concentrate (CCM) during animal studies.

Materials and methods. The study included 80 white male Wistar rats weighing $210 \pm 30$ grams at the age of 8-12 weeks, randomized into 4 groups (20 animals each): control group (C), animal did not receive treatment; control with the introduction of the cultural medium concentrate (CM) three times on days 1, 14 and 21; the introduction of MSC in a dose of 2 million cells per $1 \mathrm{~kg}$ three times on days 1, 14 and 21; the introduction of CCM in the estimated dose of 2 million cells per $1 \mathrm{~kg}$ three times on days 1,14 and 21 . Radiation burn simulation was performed (using on an X-ray unit at a dose of 110 Gray) and each animal was observed 17 times: at days 1, 7, 14, 21, 28, 35, 42, 49, 56, 63, 70, 77, 84, 91, 98, 105 and 112. Histological (stained with hematoxylin/eosin) and immunohistochemical (CD31, CD68, and VEGF) studies were performed. MSC was cultivated according to the standard procedure up to passages 3-5, the conditioned medium was collected and concentrated 10 times. The MSC immunophenotype (CD34, CD45, CD90, CD105, CD73, HLA-DR) and viability (7-ADD) were determined using flow cytometry.

Results. Under the assessment of the animal skin on the day 7 in the CCM group, the area was significantly larger compared to the $\mathrm{C}$, MSC, CM groups $(\mathrm{p}=0.05)$. In the CM group on the day 14 the area of the open wound surface and ulcers from day 28 to day 42 was significantly less, compared with the C, MSC and CCM groups ( $\mathrm{p} \leq 0.05)$. In group $\mathrm{C}$, from 42 to 77 days of observation, an increase in the area of skin ulcers was observed compared with the CM and CCM groups ( $\mathrm{p}=0.05)$. On the day 112 , healing of skin ulcers in the CM group was observed in $40 \%$, in the MSC group in $60 \%$, and only in $20 \%$ of animals in the CCM group, and in the $\mathrm{C}$ group it was not registered. Expression of VEGF marker on endothelial cells and stromal cells was observed in groups C and CM on day 28 and in groups MSCs and CCM on day 112. On the 28th day in the MSC group, the average number of vessels (CD31) in the field of view was 6.0, and on day 112 it was 12.75, $\mathrm{p} \leq 0.05$, in the CCM group - 19.10 and 28.6, respectively, $\mathrm{p} \leq 0.05$. An increase in the number of macrophages (CD68) was found in group C from 28 to 112 days (11.6 and 24.73, p $\leq 0.05$ ), and in the CM group the decrease was 22.1 and 13.07, respectively, $\mathrm{p} \leq 0,05$.

Conclusion. Thus, all used treatment modes of radiation skin lesions, including 3-fold administration of $\mathrm{CM}, \mathrm{MSC}$ and CCM at a dose of 2 million cells per $1 \mathrm{~kg}$, were effective and resulted in a reduction in the damage area, accelerated ulcer healing, and improvement of the regenerative processes. In addition, the use of MSCs led to the improvement of inflammatory processes' vascularization and reduction in the radiation skin lesions.

\section{0 \\ THE EFFECTS OF LOW-LEVEL LASER THERAPY ON FREE RADICAL REACTIONS IN RAT BLOOD WITH EXPERIMENTAL ENDOTOXIC SHOCK}

Buravlev E.A. ${ }^{1}{ }^{2}$, Machneva T.V. ${ }^{2}$, Osipov A.N. ${ }^{2}$, Vladimirov Yu.A. ${ }^{2}$

${ }^{1}$ I.M. Sechenov First Moscow State Medical University (Sechenov University), Moscow, Russia

${ }^{2}$ Pirogov Russian National Research Medical University, Moscow, Russia

evgenii.sci@gmail.com

Objective. According to photodynamic theory of laser irradiation endogenous porphyrins(EP) can be acceptors of laser irradiation. The main goal of this study was to investigate the role of EP in the effects of He-Ne laser $\left(632.8 \mathrm{~nm}, 1.5 \mathrm{~J} / \mathrm{cm}^{2}\right)$ on free radical processes in blood of rats in experimental endotoxic shock(LPS, $25 \mathrm{mg} / \mathrm{kg}$ ). 
Methods. Measurements of functional activity of polymorphonuclear leukocytes, superoxide dismutase activity(SOD) of blood plasma and erythrocytes membrane lipid oxidation were made.

Results. Exposure of the animals to LLLT increased the SOD activity by on the average of 153\% (compared with control group) in the range of EP content of 51.0 to $105.9 \mathrm{nM}$. Under the conditions of endotoxic shock action of laser irradiation was more pronounced and significantly depended on the content of EP. At the minimum (44.6 and $52.0 \mathrm{nM}$ ) and maximum (109.7 nM) concentrations of EP inhibition of SOD activity of plasma on the average of $29 \%$ was observed. And in the range of EP content of 57.4 to $90.6 \mathrm{nM}$ LLLT increased the investigated parameters on the average of $138 \%$. Similar dependence was found in the study of laser induced changes in functional activity of polymorphonuclear leukocytes in rats. In the group without endotoxic shock the level of membrame lipid peroxidation after irradiation increased of $46 \%$, in the group with endotoxic shock - of 132\%. The effect didn't depend on EP concentration in blood plasma.

Conclusion. Low-level laser therapy(LLLT) was found to have a strong impact on all the studied processes in groups of animals with LPS and control.

\section{1 \\ ORGANS ON A CHIP AS AN ALTERNATIVE TO TRADITIONAL MODELS OF CELL CULTURES AND ANIMALS}

Eliseeva Julia, Schegai Petr, Evstratova Ekaterina, Filimonova Anna

Herzen Moscow Oncology Research Institute, the laboratory of regenerative medicine and biofabrication, Moscow, Russia

julia.eliseeva@mail.ru

Objective. A convenient and modern model system is needed to study the mechanisms of the onset of various diseases, as well as to develop and test drugs. Existing standard models of cell cultures are primitive and do not allow to consider all the features of the human body and the appearance of possible adverse effects, and animal models are not sufficiently reliable in extrapolating the obtained results to humans. Organs-on-a-chip are microfluidic devices capable of physiologically relevant imitation of various human organs and tissues, can potentially be such a platform for experiments.

Methods. In this review some already-created organs-on-a-chip were characterized - kidneys, heart, skin, brain, lungs, liver, intestines, eyes, placenta and bone marrow. And also - microfluidic devices of tumors-ona-chip, which allow studying better the mechanisms of oncological diseases, as well as applying personalized treatment of patients, using their own cells and tissues in modeling diseases. In addition, attention has been paid to the development of an organism-on-a-chip, which allows for more accurate studies of the normal and pathological state of organs, the interactions between them, and also prediction of possible side effects from therapy to neighboring organs and tissues. Moreover, the situation with the development and use of organon-chip devices in the world and in Russia has been analyzed.

Results. Most importantly, these devices use directly human cells that are able to reproduce the metabolism of a person, not an animal. With the right experiment, accurate predictions of effective and toxic concentrations can be made. In addition, such devices are more economical and allow testing of combinations of compounds in various concentrations due to their parallel operation.

Despite all the advantages of organ-on-chip models, they still have a number of disadvantages that must be overcome before their widespread use and replacement of standard research methods. But there is every reason to believe that after further optimization and standardization, organ-on-a-chip models can be included in the drug development process.

Organ-on-a-chip models, coupled with bioprinter, expand the field of application of these systems and can be a key step towards the creation of automated systems for high-throughput drug screening.

Conclusion. In the future, organ-on-chip technologies can be used to improve industrial development and personalized medicine, as well as find their application in biotechnology, pharmaceutical, cosmetic and chemical companies. This system has a high potential to replace traditional models of cell cultures and animals and become a convenient alternative for scientists to use everywhere. 


\title{
12
}

\section{MECHANICAL PROPERTIES AND BIOCOMPATIBILITY OF POLYCAPROLACTONE AND GRAPHENE-REINFORCED POLYCAPROLACTONE SCAFFOLDS}

\author{
Evlashin S.A. ${ }^{1}$, Dyakonov P.V. ${ }^{1}{ }^{1}$, , Kostenko M.O. ${ }^{3}$, Kapitannikova A.Y. ${ }^{4}$, Timashev P.S. ${ }^{4}$, Rodionov S.A. ${ }^{5}$, \\ Kovalev A.V. ${ }^{5}$, Akhatov I.S. ${ }^{1}$ \\ ${ }^{1}$ Center for Design, Manufacturing \& Materials, Skolkovo Institute of Science and Technology, Moscow, Russia \\ ${ }^{2}$ Skobeltsyn Institute of Nuclear Physics, Lomonosov Moscow State University, Moscow, Russia \\ ${ }^{3}$ Kurnakov Institute of General and Inorganic Chemistry of Russian Academy of Sciences, Moscow, Russia \\ ${ }^{4}$ Institute for Regenerative Medicine, Sechenov University, Moscow, Russia \\ ${ }^{5}$ N.N. Priorov National Medical Research Center of Traumatology and Orthopaedics, Moscow, Russia \\ ${ }^{6}$ Institute for Regenerative Medicine, I. M. Sechenov First Moscow State Medical University, Moscow, Russia \\ s.evlashin@skoltech.ru
}

One of the paths of regenerative medicine further development is promotion of tissue engineering scaffolds for human augmentation. In the case of bone tissue, common materials for scaffold fabrication are such polymers as polylactide, polycaprolactone. It has been shown, that graphene combined with polymers induces material properties enhancement along with the improvement of cell adhesion and proliferation [1,2].

The aim of this study was to fabricate scaffolds of polycaprolactone and graphene-reinforced polycaprolactone by means of supercritical foaming in carbon dioxide atmosphere in order to investigate the impact of graphene incorporation upon mechanical properties and biocompatibility of scaffolds.

As a result of conducted research porous composites of graphene/polymer with various mechanical properties and spatial composition were achieved. It was observed that the increase in graphene content leads to the decrease in scaffold porosity, which results in deterioration of mechanical properties. In the meantime, foamed polycaprolactone was flexible and sustained a significant amount of mechanical load cycles (over 100 000) without structural deformation.

Cultivation of stromal cells of rabbits' costal cartilage on scaffolds lead to adhesion and distribution of cells on the surface of the material. Cells stayed alive for 14 days on the surface of the material. It is noteworthy, that migration of cells inside the matrix was not observed which tells us about non-connected pore structure characteristicd of this type of scaffold. However, taking into account biodegradability of polycaprolactone and positive results of biocompatibility tests, we believe that in vivo tests for investigation of regenerative potential of polymer/graphene scaffolds should be conducted.

\section{References:}

[1] Jakus, A. E., Secor, E. B., Rutz, A. L., Jordan, S. W., Hersam, M. C., \& Shah, R. N. (2015). Three-dimensional printing of high-content graphene scaffolds for electronic and biomedical applications. ACS nano, 9(4), 4636-4648.

[2] Holt, B. D., Wright, Z. M., Arnold, A. M., \& Sydlik, S. A. (2017). Graphene oxide as a scaffold for bone regeneration. Wiley Interdisciplinary Reviews: Nanomedicine and Nanobiotechnology, 9(3), e1437.

\section{3 \\ OPPORTUNITIES AND PROSPECTS OF REGENERATIVE MEDICINE: BIOFABRICATION OF ORGANS}

Evstratova E.S., Filimonova A.N., Shegay P.V., Eliseeva Yu.I.

FSBI "National Medical Radiology Research Center", Ministry of Health of the Russian Federation, Moscow, Russian Federation

ekevs7240@mail.ru

Objective. Recent advances in the field of regenerative medicine indicate that there is a possibility of real alternatives to the transplantation of donor organs. Tissue engineering can ensure the replacement of an entire organ or the restoration of a function in a specific area. The biomaterials used create a three-dimensional space in which cells can attach, grow and form new tissues with an appropriate structure and function. Modern scientists pay special attention to the choice of materials and methods to ensure the mechanical and physiological properties of the newly created tissue. 
Methods. We reviewed the results of modern research in the field of regenerative medicine to create hollow organs that can be a substitute for donor organs. The study of interactions between cells in the body led to an understanding of the processes of growth and differentiation of tissues.

Results. Researchers combine artificially obtained materials with cell biology concepts, creating a new field of research. Currently, research in the field of regenerative medicine is carried out for almost every type of tissue and organ in the human body. Recent progress suggests that artificial tissues may have expanded clinical applicability in the future and may be a viable therapeutic option for those who need tissue and organ replacement.

Conclusion. There are already many possibilities for using the current generation of bioengineering organs: the study of the physiology of organs and tissues, matrix biology, developmental biology, and stem cell differentiation studies.

\section{4 \\ DYNAMIC CHANGES OF EXTRACELLULAR MATRIX IN HYPERTROPHIC SCARS MODELLED IN LABORATORY RABBITS}

Fayzullin Alexey, Kapitannikova Alina, Mudryak Daniil, Tokarev Mark, Khristidis Yana, Zakharkina Olga, Ignatieva Natalia, Shekhter Anatoly

I. M. Sechenov First Moscow State Medical University, Moscow, Russia

a.kapitannikova@gmail.com

Introduction. We aimed to study hypertrophic scars from a standpoint of dynamic changes in the extracellular matrix.

Materials and methods. The experiment was performed in 12 laboratory chinchilla rabbits. Surgical scars were modelled on the ventral side of the ear. After 30, 60, 90 and 120 days, histological slides of the scars were prepared and stained with hematoxylin and eosin and Picrosirius red. Morphological analysis was performed by simple, phase-contrast, polarized light microscopy with a LEICA DM4000BLED microscope. An immunohistochemical study was performed to identify collagen type I. Amino acid analysis evaluated the composition of collagen. We applied spectrophotometry to determine the content of glycosaminoglycans. Immature and mature fractions of collagen were assessed by differential scanning calorimetry. Morphometric analysis was performed using Cellprofiler and Ilastik software. Data analysis was performed with Graphpad Prism 8.

Results. Microscopy and morphometry of the samples revealed qualitative and quantitative signs of fibrosis. Phase-contrast microscopy demonstrated the specific architectonics of collagen fibers in the scar tissues. Polarized light microscopy showed weak anisotropy at day 30 and intensive anisotropy at days 60-120. Amino acid analysis and spectrophotometry identified regeneration-specific changes in the extracellular matrix at days 30,60. Immunohistochemistry determined the main component of the scar matrix collagen type I. DSC revealed a significant content of immature collagen on days 30 and 60 of the experiment.

Conclusions. A complex profiling of extracellular matrix of the modelled scar tissues allowed us to identidy the first 60 days of the scar formation as a period of active regeneration.

\section{5 \\ PROSPECTIVE COMPARATIVE STUDY OF EXTRACTS ON THE BASE OF IRAN ENDEMIC CROCUS SPECIES FOR PERIODONTAL DISEASE}

Fetisova A.N., Mohammad Sheikhjami Karizi

Department of Chemistry, Sechenov First Moscow State Medical University (Sechenov University), Moscow, Russia

fetisova.an@sechenov.ru

Background. The pharmaceutical uses of saffron largely disappeared with the advent of synthetic chemistry medicines production. However, in recent years there has been growing interest in demonstrating saffron's already known wide pharmacological activity based on the presence of the crocetin and its glycisidic esters - crocins, and safranal - and to the synergy between the biological active chemical compounds. 
The most researches concerns studying the dried stigmas of the Crocus sativus L. (saffron spice). The plants of genus Crocus contain flavonoids, glycosides, and anthocyanin biological active compounds that are proving to have anti-inflammatory and antioxidant effects. The experimental data advocates that biological active substances of saffron help in reduction of inflammatory through the inhibition of cyclooxygenase enzyme activity. This prospective investigation includes comparative study of extracts on the base of Iran endemic Crocus species for periodontal diseases.

Methods. The objects are ethanol and aqueous stigma and petal extracts of the Crocus haussknechtii Boiss. \& Reut. ex Boiss. and Crocus speciosus M. Bieb. (Bieberstein's crocus). Phytochemical analysis, analysis of antioxidant, anti-inflammatory, and antinociceptive activity, estimation of bacteriostatic and fungistatic effects in comparing with the extracts of the $C$. sativus $L$.

Prospective results. The anti-inflammatory and antioxidant activity of saffron is explained in terms of pharmacological activity of its main biological active chemical compounds such as crocin (hydrophilic carotenoid) and safranal (2,6,6-trimethyl-1,3-cyclohexadiene-1-carboxaldehyde). In independent researches was shown that these chemical compounds suppressed inflammatory pain response as well and decreased the number of neutrophils. Moreover, $C$. sativus extracts exhibited antinociceptive effects in chemically induced pain test as well as acute and/or chronic anti-inflammatory activity, and these effects might explain by presence of the complex of biological active chemical substances: flavonoids, anthocyanins, alkaloids, saponins, and tannins. In the present investigation should be identified the most pharmacologically active extracts on the base of $C$. haussknechtii and $C$. speciosus in comparing with the $C$. sativus extracts. In addition comparative evaluation of antimicrobial and antifungal activity of the stigma and petal extracts on the base of C. haussknechtii and C. speciosus on oral pathogens, namely Streptococcus mutans, Lactobacillus, and Candida albicans is planned.

Conclusion. The investigation directed to the development of the effective and safe herbal medicines combined pharmacological activity (antioxidant, anti-inflammatory, and antinociceptive effects with bacteriostatic and antifungal activities) with minimized side effect at prevention and complex treatment of periodontal diseases. Furthermore, cost reduction of the developing herbal medicines on the base of Iran endemic crocus species is planned.

\section{References:}

[1] Bagur M.J., et al. Saffron: An Old Medicinal Plant and a Potential Novel Functional Food. Molecules 2018, 23(1), 30;

[2] Forouzanfar A., et al. Evaluation of Toothpaste Containing Aqueous Saffron Stigma Extract on Gingival Indices in Patients with Marginal Generalized Plaque-Induced Gingivitis. Iran J Med Sci. 2016 May; 41 (3 Suppl): S31.

[3] Barani Karbasaki, et al. Evaluation of Antimicrobial effects of Aqueous and Alcoholic Extracts of Saffron on Oral Pathogenic Microbes (Streptococcus Mutans, Lactobacillus, Candida Albicans). Journal of Mashhad Dental School, 2016; 40 (3): 203-212.

[4] Rahimi M. Chemical and Medicinal Properties of Saffron. Bull. Env. Pharmacol. Life Sci., Vol 4[3] February 2015:69-81.

[5] Rahmani A.H. et al. Saffron (Crocus Sativus) and its Active Ingredients: Role in the Prevention and Treatment of Disease. Pharmacogn J. 2017; 9(6): 873-879.

\section{6}

\section{DIFFERENT TYPES OF CELL SOURCES FOR PRACTICAL 3D BIOPRINTING}

Filimonova A.N., Evstratova E.S., Shegay P.V., Eliseeva Yu.I.

FSBI "National Medical Radiology Research Center", Ministry of Health of the Russian Federation, Moscow, Russia

filimonowa.af@gmail.com

Objective. Today, one of the main areas of research is the development of technologies for creating implantable bio-artificial systems consisting of a framework based on biocompatible materials and viable functioning cells. Bio-artificial systems combine the properties of living and inanimate matter. Their main purpose is the complete or partial replacement of the function of lost organs or tissues. Bio-artificial systems implanted into the human body are a kind of bio-incubators that provide cells with the necessary conditions for proliferation, differentiation and functioning.

Methods. Recently, it has been suggested that the therapeutic function of such systems consists in biostimulation of regeneration of the own cells of damaged organs and tissues of the recipient. In order to maintain long-term function after implantation, the bioprinted construct must be able to maintain cellular homeostasis, self-renew, respond to tissue damage or injury, and integrate with host tissue or organ. 
Results. Host immune response may be triggered by the implantation of exogenous cells. Therefore, the autologous source of cells is the preference, autologous cells may be obtained from the patients themselves through the generation and differentiation of autologous stem cells or through reprogramming approaches, to avoid negative immune responses. However, some limitations make it difficult to apply autologous cells in bioprinted constructs for tissue regeneration. Examples of these challenges are: technique restrictions on the isolation and in vitro culture of cells, finite expansion or regeneration capacity of many primary cell types, and the effectiveness of patient-sourced cells. Pluripotent stem cells including embryonic stem cells (ES) and induced pluripotent stem cells (iPS) are promising cell types due to their ability to proliferate in an undifferentiated but multipotent state (self-renewal) and their capability to generate multiple functional tissuespecific cell phenotypes. Especially, iPS derived directly from adult tissues requires reprogramming the cell type thus overcoming the difficulty and limitations associated with the current cell sources. Adult mesenchymal stem cells from bone marrow, fat, umbilical or other sources can differentiate into osteoblasts, chondrocytes, adipocytes, cardiac cells, endothelial cells, smooth muscle cells, hepatocytes, and neural cells and can be used in many biomedical applications. Although they have a more limited multipotent differentiation potential, they are considered safer for clinical uses and show great promise for bioprinting applications. According to previous studies, high cell viability can be obtained through optimizing the printing parameters; overall the printing processes have no adverse effects on the stem cell proliferation and differentiation abilities.

Conclusion. The 3D printed constructs for the complex tissue or organ regeneration need to be fabricated with either functional primary cells with supporting cells or progenitors/stem cells for further differentiation. In cellular printing, multiple bioinks with different cells need to be prepared to print in parallel, requiring complicated and precise control of the printing step. Additionally, acellular printing is difficult to post-seed specific cells on the desired regions of complex 3D structure. Printing stem cells with the regional bioactive factors, or post-seeding stem cells on the construct with the regional bioactive factors, may reduce the complication of the fabrication process for complex tissue/organ regeneration. Stem cells can be differentiated into target cell types by bioactive factors in the combination of location or spatial arrangement. Therefore, 3D stem cell printing can provide a simple and effective approach for regenerating complex tissue/organ.

\title{
17 \\ DECELLULARIZATION OF THE AORTIC ROOT IN SUPERCRITICAL CARBON DIOXIDE MEDIUM
}

\author{
Gafarova E.R. ${ }^{1}$, Kapomba B.S. ${ }^{1}$, Kuryanova A.S. ${ }^{1}, 2$, Bazhanov I.A. ${ }^{1}$, Churbanov S.N. ${ }^{1}$, Grebenik E.A. ${ }^{1}$, Timashev P.S. ${ }^{1,2,3}$ \\ ${ }^{1}$ Institute of Regenerative Medicine, Sechenov First Moscow State Medical University, Moscow, Russia \\ ${ }^{2}$ Department of Polymers and Composite Materials, Semenov Institute of Chemical Physics, Moscow, Russia \\ ${ }^{3}$ Institute of Photonic Technologies, Federal Scientific Research Center "Crystallography and Photonics", \\ Russian Academy of Sciences, Moscow, Russia \\ alvira.1993@mail.ru
}

Pathology of the aortic valve remains one of the most challanging problem for cardiovascular surgery. The limitations of existing prostheses require finding new approaches to help patients who need aortic valve replacement. The tissue-engineered heart valve portends a new era in the field of valve replacement techniques. One of the most promising techniques for tissue and organ regeneration is transplantation of decellularized tissues.

We attempted to decellularize ovine aortic valves in the supercritical carbon dioxide medium (scCO2), which can reduce the processing time thereby reducing the risk of contamination. We evaluated the effectiveness of our protocol by histochemical staining (hematoxylin-eosin staining) and determining of the biomechanical properties of the treated valves.

The hybrid treatment with detergent solutions for 24 hours and the subsequent extraction in scCO2 medium for 3 hours ( $\mathrm{t}=37 \mathrm{C}, \mathrm{P}=15-25 \mathrm{MPa}$ ) made it possible to extract cells whilst maintaining the extracellular matrix structure. Mechanical tests showed a slight increasing of the Young's modulus, maximum 
stress and maximum elongation in the treated tissue compared with the native. Thus, the combined treatment (detergent + scCO2) makes it possible to obtain cell-free intact matrices.

The research is supported by the Russian Foundation for Fundamental Research grant \#18-33-00982 and grant from Sechenov University.

18

\section{REGULATION OF OSTEOGENIC DIFFERENTIATION IN MESENCHYMAL STEM CELLS BY GLYCOGEN SYNTHASE KINASE-3 $\beta$ GENE KNOCKDOWN}

Galitsyna E.V., Bukharova T.B., Krivosheeva I.A., Skoblov M.Yu., Goldstein D.V.

Federal State Budgetary Scientific Institution "Research Centre for Medical Genetics" (RCMG), Moscow, Russia snowbars888@yandex.ru

Existing methods for replenishing bone defects resulting from traumatic or degenerative diseases are not sufficiently effective. To ensure histotypic regeneration in the area of damage, new therapeutic approaches are needed to regulate the differentiation of osteogenic progenitor cells. One of the osteogenesis inhibitors

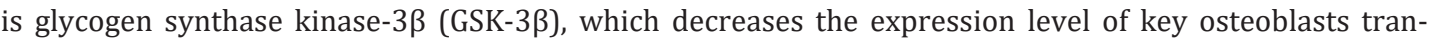
scription factor Runx2 by phosphorylation of $\beta$-catenin. Reducing GSK-3 $\beta$ mRNA levels by knockdown of siRNAs can significantly increase osteogenic differentiation efficiency of progenitor cells in the process of reparative osteogenesis.

The aim of this Study was to evaluate the impact of GSK-3 $\beta$ knockdown on the mesenchymal stem cells (MSCs) osteogenic differentiation development.

Materials and methods. Human adipose tissue-derived mesenchymal stem cells (hADSCs) were transfected with $50 \mathrm{pmol} / \mathrm{ml}$ of siRNAs molecules in a 24-well culture plate in 5\% FBS-containing Opti-MEM medium (Thermo Fisher Scientific, USA) for 24 hours. Liposomal delivery systems METAFECTENE® PRO (Biontex, USA), Lipofectamine ${ }^{\circledR} 2000$ (Thermo Fisher Scientific, USA) and TurboFect polycation system (Thermo Fisher Scientific, USA) were used to select the transfection conditions. The transfection efficiency control was performed by a comparable in length to experimental siRNAs molecules with a fluorescent 6-FAM label. Four siRNAs molecules associated with the different exons of GSK-3 $\beta$ were selected for the implementation of the knockdown. The GSK-3 $\beta$ and Runx 2 mRNAs expression levels was estimated using RT-PCR analysis.

METAFECTENE® PRO
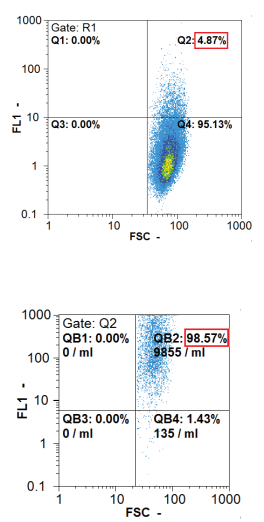

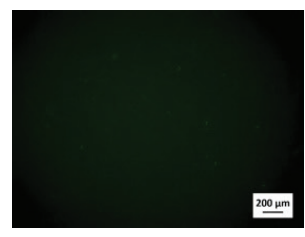

$\stackrel{200 \mu \mathrm{m}}{=}$

TurboFect
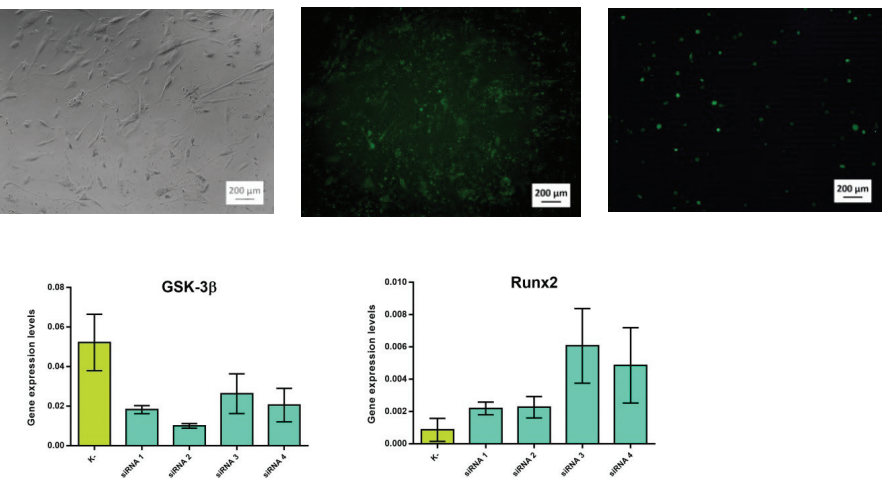

Lipofectamine® 2000

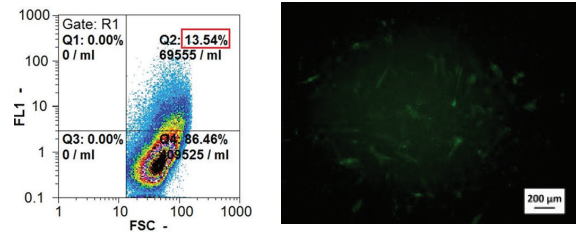

인

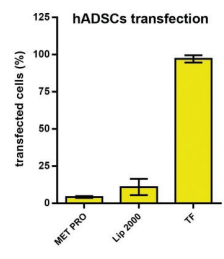

Fig. 1. Expression levels of GSK-3 3 and Runx2 in hADSCs on the 5th day after transfection was determined by RT-PCR analysis. 
Results. TurboFect, a highly efficient delivery system based on cationic polymers was selected. It's providing $97.2 \pm 2.4 \%$ of transfected cells in hADSCs cultures. On the 5 th day of the experiment, the expression levels of GSK-3 $\beta$ in these cultures decreased 2.3-5.2 times, while the transcription of Runx2 increased 2.5-5.8 times depending on the siRNA used.

Thus, it was shown that the efficiency of osteogenic differentiation in MSCs cultures can be enhanced by knockdown of the GSK-3 $\beta$ gene using siRNAs molecules.

This work was supported by the state assignment for the Federal State Budgetary Institution.

\section{9 \\ WHERE BIO MEETS NANO AND FEMTO: CONTROLLED MODIFICATIONS BY FEMTOSECOND LASER PULSES UNDER BIOLOGICALLY RELEVANT CONDITIONS FOR BIOMEDICAL APPLICATIONS}

Gruzdev Vitaly

Department of Physics and Astronomy, University of New Mexico, Albuquerque, NM, 87131, USA

vgruzdev@unm.edu

Use of ultrashort laser pulses for biomedical research and applications delivers novel techniques and potentially groundbreaking technologies for biology and medicine. Of special interest for the medical applications are the minimum invasive laser technologies that affect specific cells or tissues without destructive affecting of surrounding tissues. Metal nanoparticles are considered as a tool to obtain the minimum invasive effect since they highly localize absorption of laser energy. Of even more interest are capabilities to control biological processes at molecular level. Ultrashort (also named as femtosecond) laser pulses are the most promising tools for those technologies since they are capable of producing the unique action on matter that is highly concentrated both in time and space. In this talk, we overview controlled modification of biomolecules and controlled destruction non-thermal of nanoparticles in a polar liquid under air environment and room temperature. Both of them promise revolutionizing applications for treatment of cancers and other diseases, novel biotechnologies, production of new chemicals for pharmacology, and fundamental research on bio-engineering at molecular and nano-scale.

Recent experiments on peptides and proteins [1] demonstrated totally controlled modification of the biomolecules by femtosecond laser pulses in polar liquids (water and water mixtures with methanol acetonitrile) under room temperature in air atmosphere. By proper choice of laser parameters and composition of atmosphere, single and double formylation combined with oxidation were obtained on specific side chains of the molecules. Since the side chains control functions of peptides and proteins, those results suggest controlled modification of biological processes at molecular level by a proper permanent modification of specific biomolecules. Analysis of potential mechanisms of those chemical modifications suggest non-thermal effects that are highly favorable for the minimum invasive methods.

The non-thermal effects are also favorable for extremely gentle and controlled disassembling of specific metal nanoparticles under the biologically relevant conditions, e. g., in polar liquids (water) under air environment at room temperature [2]. The metal nanoparticles are currently employed for either photothermal treatment of cancers based on melting and local boiling, and for safe delivery of chemical substances in chemical therapy of cancers. For the latter application, the nanoparticles are coupled to molecules of the substances to passivate them during the trip through patient's body. Upon arrival at a cancer, that nanoparticle-molecule complex should be accurately disassembled without destruction of the attached molecules. The femtosecond laser pulses can solve this non-trivial problem. This approach can substantially advance the current methods of chemical therapy of cancers.

References:

[1] V. Gruzdev, D. Korkin, B. Mooney, et al, "Controlled modification of biomolecules by ultrashort laser pulses in polar liquids", Sci. Rep., v. 7 (1), p. 5550 (2017).

[2] D. Suresh, V. Gruzdev, R. Kannan, "Non-thermal nanomodification of metal nanoparticles in polar liquids", Nature Nanotech. (submitted) (2019). 
20

\title{
EFFECTS OF CYTOCHALASIN D ON CHONDROSPHERES BIOMECHANICAL PROPERTIES AND TISSUE FUSION
}

\author{
Gryadunova A.A. ${ }^{1}{ }^{2}$, Bulanova E.A. ${ }^{1}$, Koudan E.V. ${ }^{1}$, Parfenov V.A. ${ }^{1}$, Pereira F.D.A.S. ${ }^{1}$, Chernikov V.P. ${ }^{3}$, \\ Kasyanov V.A. ${ }^{4,5}$, Khesuani Y.D. ${ }^{1}$, Mironov V.A. ${ }^{1,2}$ \\ ${ }^{1}$ Private laboratory for Biotechnological Research, 3D Bioprinting Solutions, Moscow, Russian Federation \\ ${ }^{2}$ Institute for Regenerative Medicine, I.M. Sechenov First Moscow State Medical University, Moscow, \\ Russian Federation \\ ${ }^{3}$ Institute of Human Morphology, Russian Academy of Science, Moscow, Russian Federation \\ ${ }^{4}$ Riga Stradins University, Riga LV-1007, Latvia \\ ${ }^{5}$ Riga Technical University, Riga LV-1658, Latvia \\ agryadunova@bioprinting.ru
}

Introduction. Chondrospheres can be characterized as densely packed tissue spheroids generated from chondrocytes. They have become widely used in clinical practice over the past decade. However, the role of actin cytoskeleton as one of the structural determinants of chondrospheres biomechanical properties as well as the role of actin microfilaments in chondrospheres fusion behaviour has not been systematically studied yet. The aim of this study was to elucidate the role of actin cytoskeleton in the determination of biomechanical properties of chondrospheres and their tissue fusion kinetics.

Materials and Methods. Tissue spheroids with cell concentration 8000 chondrocytes per spheroid were formed using 96-wells spheroid microplates (Corning, USA) according to the manufacturer's protocol. Tissue spheroid fusion assay was performed using 96-wells spheroid microplates (Corning, USA). The biomechanical properties of tissue spheroids were measured using a micro-scale parallel-plate compression testing system Microsquisher (CellScale, Canada) and corresponding SquisherJoy software.

Results and Discussion. Chondrospheres exhibited altered cell morphology after actin depolymerisation and a considerable increase in tissue spheroids volume. Treatment with cytochalasin D dramatically reduces chondrospheres modulus of elasticity from $2,74 \pm 0,15 \mathrm{kPa}$ in control group to $0,80 \pm 0,12 \mathrm{kPa}$ after actin depolymerisation. Furthermore, treatment with cytochalasin $\mathrm{D}$ disables chondrospheres tissue fusion for 6 days of incubation.

Conclusions. Our work describes, for the first time, significant reduction of biomechanical properties of chondrospheres treated with cytochalasin D. Additionally, significant correlation has been found between depolymerisation of actin cytoskeleton and chondrospheres capacity of tissue fusion. Actin microfilaments therefore appear to be involved in cell migration mechanisms enabling tissue spheroids fusion behaviour.

\section{1}

\section{LAYERS OF THE COMPOSITE BIONANOMATERIAL AS THE STRAIN SENSOR}

Ichkitidze Levan ${ }^{1,2}$, Gerasimenko Alexander ${ }^{1,2}$, Telyshev Dmitry ${ }^{1,2}$, Kitsyuk Eugene ${ }^{3}$, Petukhov Vladimir ${ }^{1}$, Demidenko Natalia ${ }^{1}$

${ }^{1}$ Institute of Biomedical Systems of National Research University of Electronic Technology "MIET", Moscow, Russia

2I.M. Sechenov First Moscow State Medical University, Moscow, Russia

${ }^{3}$ SMC "Technological Centre", Moscow, Russia

ichkitidze@bms.zone

Objective. In medical practice, it is necessary to control the movements of various parts of the body: limbs, joints, chest, as well as swelling, tumors, deformation of muscle tissue in the framework of postoperative therapy, etc.

We investigated prototype of the strain sensor (tensoresistor) based on the layers of the bionanomaterial contained bovine serum albumin (BSA - matrix) and multi-walled carbon nanotubes (MWCNT - filler).

Methods. The aqueous dispersion of 25 wt.\% BSA/0.3 wt.\% MWCNT was applied by screen printing on flexible polyethylene terephthalate substrates. After drying layers by the laser irradiation $(\sim 970 \mathrm{~nm})$ various parameters of layers were controlled, i.e. resistance $R$, bending angle $\theta$, number of cycles $n$, measurement time, etc. One measurement cycle corresponded to a change within the range $\theta \approx \pm 150^{\circ}$. The layers of BSA/ MWCNT bionanomaterial were thickness $\sim 0.5 \div 1.5 \mu \mathrm{m}$. 
Results. The slopes of $S_{\theta}=\left(1 / R_{0}\right) \mathrm{d} R / \mathrm{d} \theta$ of the $R(\theta)$ curves were considered to be strain-sensitivities, where $R_{0}$ is the resistance of the sensor with $\theta=0$. It was found that with increasing the number $n, R$ and $S_{\theta}$ increase and the hysteresis on $R(\theta)$ decreases. For the tensoresistor obtained: specific resistances $\sim 0.1 \div 1 \Omega \cdot \mathrm{m}, S_{\theta} \sim 1.0 \div 1.5 \%$ /grad, linear strain sensitivity $S \sim 160$. These results are high.

Conclusion. The examined layers of the bionanomaterial BSA/MWCNT as a strain sensor is of a particular interest for medical practice. In particul he considered strain gauges can be implemented by applying a water dispersion of nanomaterials to human skin using a 3-D printer for monitoring: movements (arms, blinking) and detection of signs of pathology (dysphagia, respiratory diseases, angina, et. al.).

This study was supported by the Russian Science Foundation, project No.18-79-10008.

\title{
22 \\ MAGNETIC FIELD SENSOR AND THE POSSIBLE ITS APPLICATIONS IN MEDICAL DIAGNOSTICS
}

\author{
Ichkitidze Levan ${ }^{1,2}$, Belodedov Michael ${ }^{3}$, Selishchev Sergei ${ }^{1}$, Telyshev Dmitry ${ }^{1,2}$ \\ ${ }^{1}$ National Research University of Electronic Technology, Zelenograd, Moscow, Russia \\ 2I.M. Sechenov First Moscow State Medical University, Moscow, Russia \\ ${ }^{3}$ Bauman Moscow State Technical University, Moscow, Russia \\ ichkitidze@bms.zone
}

Objective. In biomedical applications, magnetic field sensors (MFS) with ultra-low threshold sensitivity $\delta B \leq 1 \mathrm{nT}$ are in demand. The detected ceramic high-temperature superconductors (HTSC) showed the properties of the Josephson medium and based on them were proposed prototype of the MFS in the mode of magnetic modulation (MM). We investigated the differential MM MFS based on ceramic HTSC material of the system Bi-2223.

Methods. A magnetically sensitive sensor element served as a cylindrical rod made of ceramic with a length of $10 \mathrm{~mm}$ and a diameter of $2 \mathrm{~mm}$. The useful signal was the response $U_{2}$ (voltage) at the second harmonic. The excitation frequency $f$ varied in the range of $5 \div 50 \mathrm{kHz}$, and the selectivity of the harmonics provided a selective nanovoltmeter at $40 \mathrm{~dB}$ /octave.

Results. It was established that the useful signal $U_{2}$ linearly depends on $f$, and also the magnetosensitivity $S=\mathrm{d} U_{2} / \mathrm{d} B$ grows linearly from $f$. The experiment recorded: $S \sim 500 \mathrm{~V} / \mathrm{T}, \delta B \sim 20 \mathrm{pT}$, the dynamic measurement range $\sim 120 \mathrm{~dB}$. Magnetic field measurement range was $\pm 0.6 \mathrm{mT}$. Estimates showed that with optimal selection $f$, the number of turns, selectivity, the identity of the two parts of the rod, the threshold sensitivity can be reduced significantly and make $\delta B \leq 2 \mathrm{pT}$.

Conclusion. The investigated differential weak magnetic-field magnetomodulation sensor based on the Bi-2223 HTC ceramic material has a number of parameters typical of ferroprobe transformers, including the possibility of measuring the absolute value of the magnetic field, simple design and fabrication, high magneticfield sensitivity, and an accompanying electronic system. This magnetic field sensor can be used in magnetocardiography, as well as for non-invasive registration of magnetic particles and control of various implantable devices or artificial organs in biological objects.

This work was supported by the Russian Science Foundation, project No. 18-79-10008.

23

\section{COBALT-INDUCED HEMATOLOGICAL CHANGES IN IMMATURE MICE}

Ivanov I. ${ }^{1}{ }^{2 *}$, Gluhcheva $Y .{ }^{1}$, Pavlova E. ${ }^{1}$, Petrova E. ${ }^{1}$, Tinkov A. A. ${ }^{3}$, Skalny A. V. ${ }^{3}$

${ }^{1}$ Institute of Experimental Morphology, Pathology and Anthropology with Museum - Bulgarian Academy of Sciences, Sofia, Bulgaria

${ }^{2}$ National Sports Academy "Vassil Levski", Sofia, Bulgaria

${ }^{3}$ P. G. Demidov Yaroslavl State University, Yaroslavl, Russia

ivanmirchev@abv.bg

Background. In earlier years cobalt chloride $\left(\mathrm{CoCl}_{2}\right)$ was used as anti-anemic agent, but nowadays, it is the most commonly used agent in experimental models for inducing chemical hypoxia. 
Objective. The aim of the present study was to evaluate the effect of subacute $\mathrm{CoCl}_{2}$ exposure on hematological parameters in immature mice in relation to iron ( $\mathrm{Fe}$ ) metabolism.

Methods. Pregnant ICR mice were subjected to a daily dose of $75 \mathrm{mg} / \mathrm{kg}$ body weight $\mathrm{CoCl}_{2} \times 6 \mathrm{H}_{2} \mathrm{O} 2-3$ days prior delivery and treatment continued until postnatal days 18 and 25. The compound was dissolved and administrated with drinking tap water. Age-matched mice obtaining regular tap water were used as control groups.

Results: The results show significant increase in erythrocyte count (RBC) and hemoglobin (Hb) content in day $25 \mathrm{CoCl}_{2}$-treated mice compared to age-matched control animals and d18 Co-exposed mice. Although $\mathrm{Hb}$ was increased the $\mathrm{Hb}$-related parameters - MCH and MCHC were significantly decreased. Exposure to $\mathrm{CoCl}_{2}$ induced significant accumulation of $\mathrm{Co}^{2+}$ in blood sera and erythrocytes of the exposed mice. Simultaneously, Fe content was also significantly increased in sera and erythrocytes of Co-exposed d25 mice which corresponds with the increased $\mathrm{RBC}$ and $\mathrm{Hb}$ content.

Conclusion. The obtained data suggest a time-dependent stimulatory effect of subacute $\mathrm{CoCl}_{2}$ exposure on the hematological parameters. Nevertheless, the increased RBC may be a result of a feed-back mechanism to compensate the reduced cell volume to meet the body's oxygen demands.

Acknowledgements. The study was supported by Grants No. DNTS/Russia 02/1/14.06.2018 from the Bulgarian National Science Fund and No. 18-54-18006 from the Russian Foundation for Basic Research.

\section{4 \\ EFFECT OF CYTOCHROME C-PHOSPHATIDIC ACID COMPLEX ON THE MEMBRANE STRUCTURE OF LIPOSOMES}

Kirilina I.V. ${ }^{1}$, Stepanov G.O. ${ }^{1}$, Buravlev E.A. ${ }^{1,2}$, Osipov A.N. ${ }^{1}$

${ }^{1}$ Pirogov Russian National Research Medical University, Moscow, Russia

2I.M. Sechenov First Moscow State Medical University (Sechenov University), Moscow, Russia

kirilina-irina@bk.ru

Objective. One of the most well-known mechanisms for starting the internal pathway of apoptosis is to increase the permeability of the outer membrane of mitochondria and release of cytochrome $c$ from the intermembrane space to the cytosol. This pathway is initiated by apoptotic proteins in the BCL-2 family, including Bax and Bak. The formation of cytochrome $c$-lipid complex is an alternative way of the formation of pores in the membrane and release of cytochrome $c$. Cytochrome $c$ electrostatically interacts with anionic phospholipids, such as cardiolipin, phosphatidylserine, phosphatidylinositol and phosphatidic acid. Phosphatidic acid can be obtained by the enzyme phospholipase $D$ (also present in mitochondria), which produces phosphatidylcholine phosphatidic acid.

Methods. Fluorescent method for release of fluorescent dye(5,6-carboxyfluorescein) and chemiluminescent method for peroxidase activity of cytochrome $c$ were used.

Results. Operating time of phosphatidic acid under the action of phospholipase $D$ (from Arachis hypogaea) led to an increase in the association of cytochrome $c$ with the membrane. Dissociation constants were: 0 minutes of incubation with phospholipase $D-K_{d}=3.9 \cdot 10^{-5} \mathrm{M}^{-1}, 60$ minutes $-K_{d}=3.3 \cdot 10^{-5} \mathrm{M}^{-1}$.

Conclusion. Peroxidase activity of cytochrome $c$ during incubation with phospholipase $D$ for 60 minutes increased 4 times compared to 0 minutes of incubation. The rate of release of fluorescent dye from liposomes, through the pores formed in the membrane during interaction with cytochrome $c$ was estimated by the pitch of the angle of kinetic fluorescence and incubation with phospholipase $D$ for 60 minutes was almost 2 times more than during incubation 0 minutes.

\section{5}

\section{LEFT VENTRICLE MOCK-UP WITH CARDIAC ELECTRICAL PROPERTIES}

Korn L., Lyra S., Leonhardt S., Walter M.

Medical Information Technology, RWTH Aachen University, Aachen, Germany

korn@hia.rwth-aachen.de

In cardiogenic shock (CS) the heart muscle is not able to pump a sufficient amount of blood into the periphery and therefore, inadequate supply of oxygen and nutrition to the organs may occur. For the 
treatment of CS, Ventricular Assist Devices (VADs) are used for pumping blood from the left ventricle into the aorta, so that the heart muscle can recover and life-essential blood flow into the circulatory system is achieved. Although VAD therapy has shown great success in CS treatment, there is still no consistent way to set pump speed. The optimal treatment of a patient could be achieved by physiological control, which takes the physiological state of the cardiovascular system (CVS) into account. In order to apply this strategy, parameters of the CVS have to be determined.

As an approach to this, the placement of electrodes onto a VAD enables to measure the electrical properties of the surrounding tissue, potentially ventricular volume. In order to develop our measurement technology in in-vitro tests and to validate the methodology we designed an anatomical mock-up providing a cost effective and reproducible environment. Therefore, we developed customizable heart phantoms that are integrated in a volume test bench. Various additives to the silicone material of the phantom are used to model the electrical properties of cardiac tissue. For modelling both the conductive and capacitive behaviour of tissue, we used carbon and bariumtitante and analysed these samples for amplitude and phase in the range of $1 \mathrm{kHz}$ to $100 \mathrm{kHz}$ in comparison to pure silicone samples.

\section{6 \\ EFFECTS OF METFORMIN ON OSTEOARTHRITIS DEVELOPMENT IN RATS}

Kurenkova A.D., Volkova M.V., Afanasyevskaya E.V., Chagin A.S.

Institute for Regenerative Medicine, Sechenov University, Moscow, Russia

n_kurenkova@mail.ru

Objective. It has been shown that both pharmacological and genetic inhibition of mTOR can reduce the severity of osteoarthritis (OA). Metformin, a widely used drug for diabetes type II, inhibits mTORC1 (mechanical target of rapamycin complex 1) via AMPK and TSC1 kinases. Thus, we hypothesized that metformin may have a protective effect in OA.

Methods. OA was induced employing medial meniscus tearing (MMT) model in rats at 9 weeks of age. Two independent experiments were performed: 1) mixed background rats of 90-110g were used; 2) Wistar rats of 200-260g were used. Rats received either vehicle or metformin (250mg/kg, gavage) daily starting 1 week before and ending 3 weeks after surgery.

Results. In the first experiment the body weight increased by $50 \%$ in both the metformin and control groups, in the second, $25 \%$ increase in body weight was observed in vehicle group, but no changes in the treated. The development of OA was evaluated on tissue sections stained with Safranin 0 and Fast Green. In the $1^{\text {st }}$ experiment, the average OA score on the femoral (F) and tibial (T) cartilage was 4 $\pm 0,5$ in vehicletreated group, whereas metformin reduced the score to $3.5 \pm 0.2(\mathrm{~T})$ and $3.25 \pm 0.2(\mathrm{~F})$. In the $2^{\text {nd }}$ experiment, the OA score in vehicle-treated animals was $5 \pm 0.5(\mathrm{~T})$ and $4 \pm 0.5(\mathrm{~F})$ and no effect of metformin was observed (OA score $5 \pm 0.75(\mathrm{~T})$ and $4 \pm 1.1(\mathrm{~F})$ ).

Conclusion. We concluded that despite it was reported that blocking of mTORC1 protects from OA and metformin blocks mTORC1, metformin cannot be employed as an anti-osteoarthritis therapy.

\section{7 OBTAINED BY LASER PRINTING \\ Kurilova U.E. ${ }^{1}$, Gerasimenko A.Yu. ${ }^{1,2}$ \\ ${ }^{1}$ National Research University of Electronic Technology MIET, Russia \\ ${ }^{2}$ I.M. Sechenov First Moscow State Medical University, Russia \\ kurilova_10@mail.ru}

STUDIES OF MULTILAYER THREE-DIMENSIONAL TISSUE ENGINEERING CONSTRUCTIONS

The purpose of this work is studying of surface characteristics and biocompatibility of the samples of three-dimensional cellular and tissue engineering constructions for layer-by-layer repair of tissues of heart and blood vessels. Samples components are albumin, collagen and chitosan as matrices and carbon nanotubes as reinforcement. Three-dimensional structures are formed in layers by laser printing device. 
The principle of its operation is moving the laser beam along a predetermined trajectory over a container with liquid nanomaterial; under the action of laser radiation, the water component evaporate and the nanotubes are oriented into a scaffold.

Methods of vibrational spectroscopy, AFM and SEM were used for analysis of the binding of the material components to the carbon matrix, the morphology of the resulting layers and the structural parameters of the constructions. It has been obtained that under the action of laser radiation on aqueous dispersions damage of the organic components structure is absent. Investigation of the properties showed the presence of the required surface topography favouring the proliferation of the cellular component.

The biocompatibility of the samples was evaluated after incubation of them with endothelial cells for 72 hours. It has been established that the layer consisting of albumin and nanotubes supports growth of cells the most. The morphology of the cells on the samples corresponds to the morphology of the control cells. The obtained samples can be used to repair damages in cardiovascular system.

\title{
28 \\ CONDITION MEDIUM NEURONAL PROGENITOR CELL PROTECTS AGAINST H2O2-INDUCED SH-SY5Y CELL DEATH
}

\author{
Leonov G.E. ${ }^{1}$, Salikhova D.I. ${ }^{1}$, Bukharova T.B. ${ }^{1}$, Efremova A.S. ${ }^{1}$, Kiselev S.L. ${ }^{1,2}$, Goldshtein D.V. ${ }^{1}$ \\ ${ }^{1}$ Research Center for Medical Genetics, Moscow, Russia \\ ${ }^{2}$ Vavilov Institute of General Genetics, Russian Academy of Sciences, Moscow, Russia \\ golerus@gmail.com
}

Background. Neurodegenerative diseases represent a major threat to human health. These agedependent disorders are becoming increasingly prevalent, in part because the elderly population has increased in recent years. Oxidative stress has been associated with neurodegenerative disorders. The paracrine mechanism of action of stem cell opens new therapeutic perspectives, but therapies with the proteins or cytokines produced by activated stem cells may be more practical than cell therapies.

Aim. In this research was studied the neuroprotective effect of the conditioned medium neuronal progenitor cells compared with CEREBROLYSIN ${ }^{\circledR}$ on a model H2O2 - induced oxidative stress on human neuroblastoma cells SH-SY5Y.

Materials and methods. iPS-cells were cultured in differentiation media to obtain neural stem cells (NSC). NSC were cultured in DMEM/F12, 2\% B27, FGF2 $20 \mathrm{ng} / \mathrm{ml}$, purmorphamine $(2 \mu \mathrm{M})$ for receiving neuronal progenitor cells (NPC). The oxidative stress was induced by adding $300 \mu \mathrm{M} \mathrm{H} 202$ in the culture SH-SY5Y cell line for 12 hours. NPC were cultured for 24 hours to obtain the conditioned medium (CM) and then concentrate to $0.5 \mathrm{mg} / \mathrm{ml}$ of total protein. The sample of CM and nootropic drug CEREBROLYSIN® were added to 24 hours before oxidative stress, and cell viability was measurement after 12 hours using the MTT test. Apoptotic features were observed with Hoechst 33342 staining.

MTT test

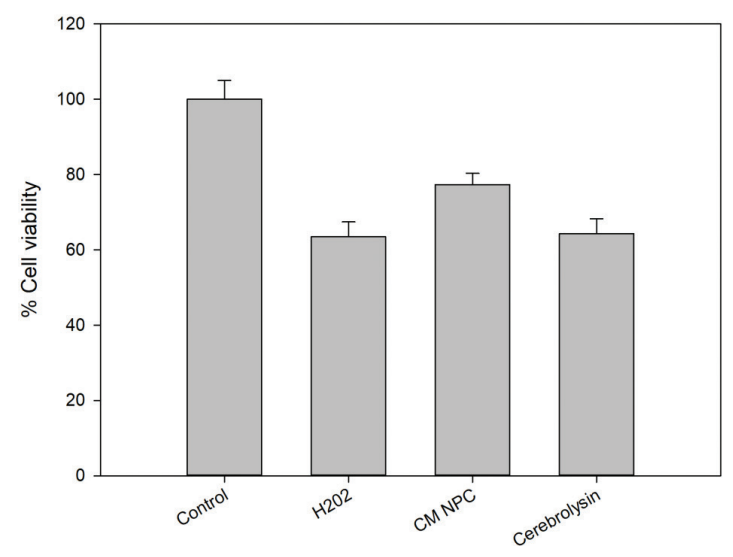

Fig.1. MTT test.
Hoechst 33342 staining

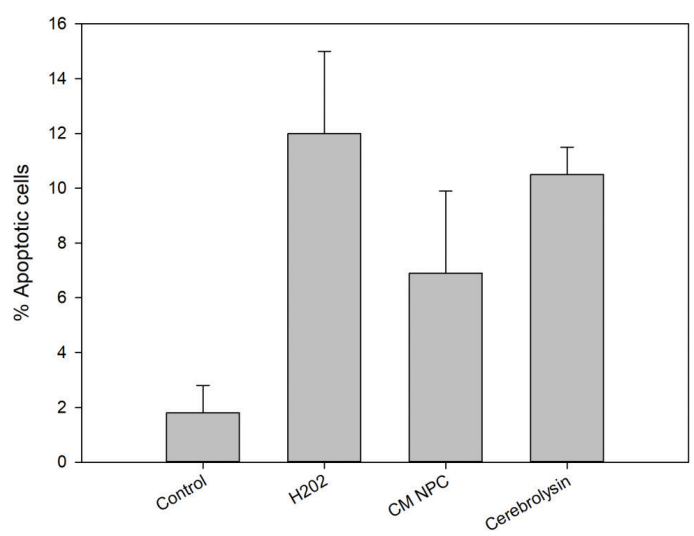

Fig. 2. Hoechst 33342 staining. 
Results. The CM of the neuronal progenitor cells were increased the viability of the SH-SY5Y cell line under oxidative stress by $13 \pm 2 \%$. the number of cells in a state of apoptosis decreased from $12 \pm 3$ to $7 \pm 2$. Cerebrolysin showed no changes in cell survival and apoptosis.

This work was supported by the Ministry of Education and Science of the Russian Federation (project no. № 14.604.21.0184 RFMEFI60417X0184) and RFBR state assignment for RCMG.

29

\section{LONG-TERM HIGH-RESOLUTION MANOMETRY (HRM) - BIG DATA MOTILITY ANALYSIS}

OttM. ${ }^{1}$, Jell A. ${ }^{1}$, Ostler D. ${ }^{1}$, Telyshev $D .{ }^{2}$, Selishev S. $^{2}$, Feußner $H .{ }^{1}$

${ }^{1}$ Department of Surgery, Klinikum rechts der Isar, Technical University Munich, Germany

${ }^{2}$ National Research University of Electronic Technology, Moscow, Russia

melanie.ott@tum.de/alissa.jell@tum.de

High-resolution manometry (HRM) of the esophagus is the gold standard in the diagnosis of esophageal motility disorders [1]. As the measurements take place in clinic for a very limited period of time only little is known about circadian changes and there is no recording of intermittent symptoms in esophageal motility. Also, the measurements are mostly concentrated on pathologies of the lower esophageal sphincter and tubular esophagus, there is only little known about the upper esophageal sphincter (UES). Therefore, we prolonged the time of measurement to a full of 24 hours and focused on the motility of the upper esophageal sphincter.

The aim of our project was to establish normal values in healthy subjects - for the long-term manometry as well as for the upper esophageal sphincter. The exact manual analysis was used as a foundation for automated analysis of the esophageal motility. Further, we wanted to identify patients with abnormal findings and determine pathological patterns when examining esophageal motor function.

Therefore, we implemented a python scripting for extracting every pressure event of the whole examination in $640 \times 480$ pixel $^{2}$ images. A typical long-term measurement generates around 1000 images which were used for clustering. Orange, a python library, commonly used for image embedding, was modified and trained with characteristic volunteer data sets as well as defined diseases (e.g. achalasia, Zenker's diverticula). We validated several common imaging neuronal networks for inter- and intra-observer accordance and received best results with Inception v3 [2].

This is a promising approach for a better understanding of the circadian changes in esophageal motility and a detailed evaluation of the upper and lower esophageal sphincter as well as the tubular esophagus.

\section{References:}

[1] Roman S, Pandolfino J, Mion F. High-resolution manometry: a new gold standard to diagnose esophageal dysmotility? Gastroenterologie clinique et biologique 2009; 33: 1061-1067

[2] Szegedy C. et al. Rethinking the Inception Architecture for Computer Vision. [Inception-v3]; 016 CVPR.

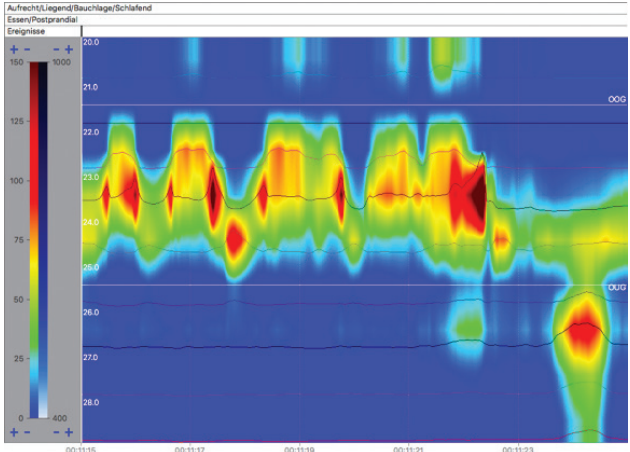

Fig. 1. Pathological findings of the upper esophageal sphincter in a patient with Wallenberg syndrome.

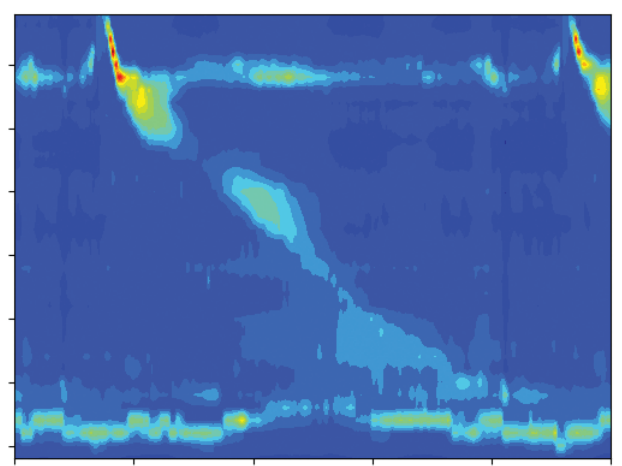

Fig. 2. Segmented HRM pressure plot of a normal swallow. 


\title{
30
}

\section{INVESTIGATION OF ELECTRICAL STIMULATION OF SKIN FIBROBLASTS GROWTH ON CARBON NANOTUBE- AND ORGANIC COMPOUND- BASED SUBSTRATES}

\author{
Privalova P.Yu. , ${ }^{1}$ Petukhov V.A. ${ }^{1}$, Gerasimenko A.Yu. ${ }^{1,2}$ \\ ${ }^{1}$ National Research University of Electronic Technology, Moscow, Russia \\ 2I.M. Sechenov First Moscow State Medical University, Moscow, Russia \\ privalova_polina@rambler.ru
}

Objective. This investigation discusses the method of electrical stimulation of skin fibroblasts growing on substrates composed by carbon nanotubes and organic compounds.

Methods. Substrates were produced from a dispersion of single-walled carbon nanotubes and organic compounds (serum albumin, collagen, chitosan) and formed by using infrared laser radiation. Laser exposure stimulated the formation of conductive nanotube clusters responsible for electrical signal transmission to the cells, and organic compounds improved cell adhesion due to the presence of cell membrane receptors sensitive to matrix proteins and aminosugar molecules. A system for electrical stimulation included an electric pulse generator, culture plate with a breadboard and electrodes made of surgical steel with gold plating. Electrodes were designed to intimate contact with the substrates and conducted to the generator through the holes in the culture plate cover. Cells were stimulated for $48 \mathrm{~h}$ with pulsed electric signal (60$200 \mathrm{mV}$ amplitude, $1 \mathrm{~ms}$ pulse duration, $1 \mathrm{~s}$ pause).

Results. The effects of electrical stimulation on the cell proliferation were estimated by MTT-test. It was found that skin fibroblasts are sensitive to the stimulus, but the most prominent increase of cell proliferation was detected at $80 \mathrm{mV}$ pulse amplitude. In these conditions, a 13 percent augmentation of cell growth rate was obtained. The formation of denser cell monolayer were achieved by fluorescent microscopy of cell nuclei stained by ethidium bromide and fluorescein diacetate. No pathological changes in cell morphology were observed.

Conclusion. The obtained results suggest that skin fibroblasts growing on nanotube- and organic compound- based substrates are sensitive to electrical stimulation. This results can be explained by the activation of potential-controlled ion channels and the stimulation of metabolic processes that accelerate cell growth.

\section{1 \\ MOBILE SYSTEM FOR MEASURING THE PARAMETERS OF PIGMENTAL NON-FORMATION OF THE SKIN}

\author{
Rimskaya E.N. ${ }^{1}$, Briko A.N. ${ }^{1}$, Schadko A.O. ${ }^{1}$, Berezhnoy P.U. ${ }^{2}$, Deshin I.A. ${ }^{1}$, Apollonova I.A. ${ }^{1}$, Nikolaev A.P. ${ }^{1}$, \\ Reshetov I.V. ${ }^{3}$ \\ ${ }^{1}$ Moscow State Technical University. N.E. Bauman, Moscow, Russia \\ ${ }^{2}$ Russian University of Economics. G.V. Plekhanov, Moscow, Russia \\ ${ }^{3}$ First Moscow State Medical University. THEM. Sechenov, Moscow, Russia \\ romehelen@gmail.com
}

Early diagnosis of malignant tumors of the skin, including melanoma of the skin, is extremely relevant and socially significant problem not only in the Russian Federation, but also abroad [1]. The effectiveness of the treatment of malignant tumors largely depends on their early diagnosis.

A promising method for increasing the effectiveness of early non-invasive diagnosis of malignant skin tumors is the use of early non-invasive diagnosis based on the analysis of clinical images [1,2].

The developed method consists in registration and subsequent digital processing of images of pigmented skin neoplasms $[2,3]$. Registration of images is carried out using a mobile phone camera. This is followed by a detailed image processing, which consists in finding the reference and its parameters. Next comes the recognition of the neoplasm itself and the determination of its parameters, such as boundaries, area, maximum and minimum diameters, the color of the pigmented skin neoplasm, the probability of malignancy $[2,3]$. 


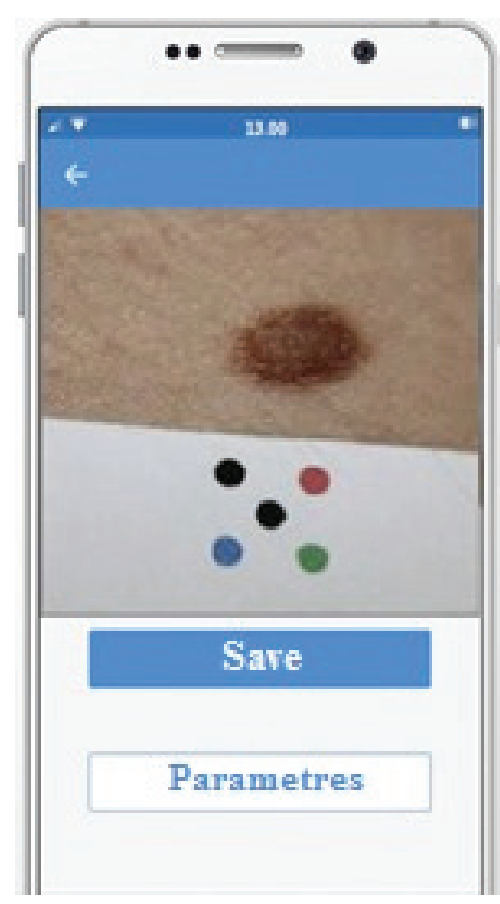

Fig. 1. Mobile system for measuring the parameters of pigmented skin neoplasms.

Acknowledgements. The processing and analysis of images of pigmented skin neoplasms was supported by the Russian Foundation for Basic Research (RFBR), project No. 18-38-00958.

Conclusions. According to the results of a study of various non- invasive diagnostic methods, a mobile system for measuring the parameters of pigmented skin neoplasms was developed.

\title{
References:
}

[1] Demidov L.V. et al. Journal of N.N. Blokhin RAMS 18 (1), 36-41 (2007).

[2] Abramovits W. et al. Clin. Dermatol. 21, 353-358 (2003).

[3] Gewirtzman A.J., et al. Br. J. Dermatol. 149, 59-63 (2003).

\section{2 \\ DEVELOPMENT OF AN AUTOMATED SEGMENTATION METHOD FOR EARLY DIAGNOSTICS OF PIGMENTED SKIN LESIONS}

\author{
and Zaytsev K.I. ${ }^{1,2,3}$ \\ ${ }^{1}$ Bauman Moscow State Technical University, Moscow 105005, Russia \\ ${ }^{2}$ Sechenov First Moscow State Medical University, Moscow 119991, Russia \\ ${ }^{3}$ Prokhorov General Physics Institute of RAS, Moscow 119991, Russia \\ romehelen@gmail.com
}

Rimskaya E.N. ${ }^{1,2}$, Apollonova I.A. ${ }^{1}$, Nikolaev A.P. ${ }^{1}$, Kudrin K.G. ${ }^{1,2}$, Chernomyrdin N.V. ${ }^{1,2,3}$, Reshetov I.V. ${ }^{2}$,

Melanoma remains the leading cause of death in patients with oncodermatology [1]. A steady increase of morbidity and mortality form melanoma is observed all over the world [1-3].

One of the important clinical signs is the border of the pigmented lesions: contour and its area $[2,4]$. The meaning of the contour detection operation is to intensify sharp changes in brightness, and since in the image such places are usually the border of objects [2-5].

To assess the quality of the automatic detection of skin pigmented lesions, the main methods for detection the contour of pigmented growth on its digital image were examined: methods based on edge detection operators (Roberts, Sobel, Canny) and the region growing $[2,5]$. 
(a)

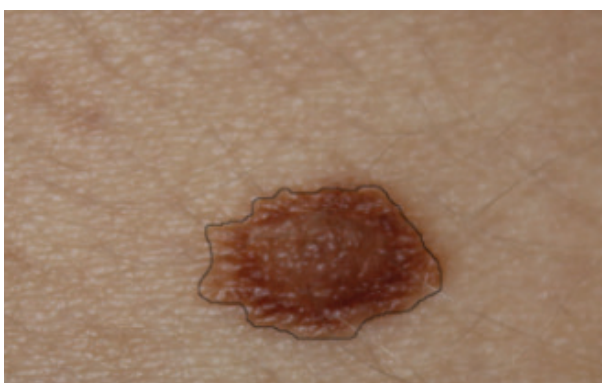

(b)

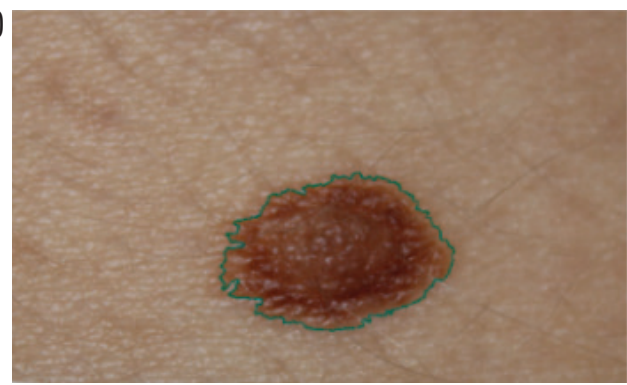

Fig. 1. (a) visual detection of the contour, (b) detection by region growing $[2,5]$.

Table 1. Table of results of all methods of contour detection

\begin{tabular}{|l|c|c|c|c|}
\hline Methods & $\mu \_\delta, \%$ & $\mu_{-} \varepsilon, \%$ & $\begin{array}{c}\text { Standard } \\
\text { deviation_} \delta, \%\end{array}$ & $\begin{array}{c}\text { Standard } \\
\text { deviation_} \varepsilon, \%\end{array}$ \\
\hline $\begin{array}{l}\text { Methods based on edge detection } \\
\text { operators: }\end{array}$ & & & & \\
\hline Roberts operator & 3.17 & 3.27 & 0.055 & 0.052 \\
\hline Sobel operator & 3.05 & 3.13 & 0.054 & 0.053 \\
\hline Canny operator & 2.93 & 3.00 & 0.055 & 0.048 \\
\hline Method of region growing & 2.79 & 2.86 & 0.055 & 0.044 \\
\hline
\end{tabular}

In our research, we tested the efficiency of the methods consisted of comparing the results of automated and visual segmentation. Each image of the lesions was segmented by software and manually, after which the errors of finding the area - $\delta$ and the error in finding the borders of pigmented skin lesions - $\varepsilon$ were calculated.

The results of the study, the best method among the methods analyzed was the region growing method. The average value of the errors of finding the area $\mu_{-} \delta$ and the error of finding the boundaries of pigmented skin lesions $\mu_{\_} \varepsilon$ do not exceed 3\%. The errors of automatic segmentation by the method of growing the regions have a low standard deviation, i.e. the method has the best repeatability.

\section{References:}

[1] Е.Н. Римская и др., Биомедицинская радиоэлектроника 7, 31-37 (2016).

[2] Е.Н. Римская и др., НИИ радиоэлектроники и лазерной техники МГТУ им. Н.Э. Баумана, 25-27 (2017).

[3] N. Eisemann et al., Journal of Investigative Dermatology 134, 43-50 (2014).

[4] Е.Н. Римская и др., Биомедицинская радиоэлектроника 8, 63-70 (2017).

[5] R.C. Gonzalez et al., Prentice-Hall, 344 (2004).

\section{3}

\section{DESIGN AND EVALUATION OF THE CHITOSAN PARTICLES FOR TISSUE ENGINEERING}

Sedyakina Natalia E., Titov Roman A., Feldman Nataliya B., Lutsenko Sergey V.

I.M. Sechenov First Moscow State Medical University (Sechenov University), Moscow, Russia nsedyakina@mail.ru

Three dimensional (3D) scaffolds manufacturing by bonding of the chitosan particles were found to exhibit a great potential as matrixes for regeneration in the field of tissue engineering [1].

The aim of this work was to obtain chitosan particles with suitable properties intended for further fabrication of 3D-scaffolds by agglomeration of the spheres for use in regenerative medicine.

The chitosan spheres were produced by ionotropic gelation followed by covalent crosslinking of the polymer matrix with a mixture of dicarboxylic acids. The mass ratio of crosslinkers was varied. The particles obtained were coated the protein (human serum albumin) as a model of the growth factor. The size, morphology, erosion and loading capacity of the particles and in vitro protein release from them were evaluated. 
The spherical particles with a smooth surface and a mass-average diameter of $1.5 \mathrm{~mm}$ were obtained. It was shown that with the increasing in the content of long-chain crosslinking agent in the mixture of crosslinkers, the loading capacity of the spheres increased from 27 to $149 \mu \mathrm{g} / \mathrm{mg}$. This can be explained by the reduction in the density of crosslinking of chitosan. The adjustable prolonged release of albumin from the particles was achieved.

Thus, the biocompatible and biodegradable spherical particles with a controlled rate of protein release were obtained. The results of this study showed that the samples can be used to produce 3D-scaffolds for tissue engineering application.

Reference:

[1] M. Kucharska, K. Walenko, B. Butruk, T. Brynk, M. Heljak, T. Ciach. Mater. Lett., 2010, 64: 1059-1062.

\section{4 \\ FUNCTIONAL PROPERTIES OF GRANULOCYTES' SURFACE IN THE MECHANICAL STRESS CONDITIONS}

Skorkina M.Yu ${ }^{1}$, , Zernakova N.I. ${ }^{1}$, Shamray E.A. ${ }^{1}$, Belyaeva S.S. ${ }^{2}$

${ }^{1}$ Belgorod state National Research University, Belgorod, Russia

${ }^{2}$ St. loasaf Regional hospital, Hematological department, Belgorod, Russia

skorkina@bsu.edu.ru

Introduction. The purinergic signaling system regulates key aspects of many physiological processes including the activation of the various types of immune cells. The aim of current work was studied the functional properties of granulocytes in norm and at the development of acute lymphoblast leukemia (ALL) during modeling the mechanical stress (in vitro).

Material and methods. In the experiment the blood of healthy people $(n=30)$ and patients with ALL $(n=30)$ was used. Blood samples were collected into the vacuum tubes Vacuette K3E. The blood samples were subjected to the deformation stress in vitro. In the experiment, the model of stress injection was used. In the samples measured the ATP concentration. The functional activity of a cell's surface is closely related to biophysical properties of plasmalemma that it was studied by atomic force microscopy (AFM) approaches. The stiffness of the cell's surface was estimated by numeric curves of Young's module that measured by AFM in the force spectroscopy mode. The potential of the surface of granulocyte's membrane was evaluated in the Kelvin probe mode. The adhesion force in the system "erythrocyte-granulocyte" was performed in the force spectroscopy mode. The migration activity of granulocytes was investigated in the direct capillary test taking into account cell viability not less $95 \%$.

Results. In the group patients with ALL on the treatment stage found the decrease ATP concentration by $63.7(\mathrm{p}<0.05)$ as compared with group healthy people. The stiffness of granulocytes' surface decreased by $56.7 \%(\mathrm{p}<0.05)$, and surface potential of granulocytes and adhesion force between erythrocyte and granulocyte increased accordingly by $46.9 \%(\mathrm{p}<0.05)$ and $87.9(\mathrm{p}<0.05)$ as compared with healthy people. In the group of ALL under the influence of mechanical stress, the percent of migrated granulocytes was decreased by $17.4 \%(p<0.05)$ as compared with the group of healthy people.

Conclusion. Thus, in the group of ALL on the treatment stage was observed the changes in the functional properties of granulocytes. It was established that stimulation of elements purinergic signaling system on the mechanical stress model in vitro in the group of ALL was accompanied by decreased ATP release from blood cells as compared with similar conditions in the blood healthy people. In the group of patients with ALL the stiffness of granulocytes' surface decreased against the background increase of the potential of surface which entails increasing the adhesion force in the system "erythrocyte-granulocyte". Changes of functional properties of granulocytes' surface and increase the adhesion force between erythrocyte and leukocyte in the bloodstream limit the migration activity of granulocyte that is the result weakens realization of immune reactions of granulocytes in the pathological conditions of the blood system.

The reported study was funded by the Russian Foundation of Basic Research (RFBR) according to the research project № 18-015-00032\19. 


\section{5 \\ EDITING ON RNA AND DNA LEVELS OF DYSFERLIN GENE EXON 26 FOR DYSFERLINOPATHY TREATMENT}

Starostina I.G., Agliullina D.R., Shaimardanova A.A., Yakovlev I.A, Solovyeva V.V., Deev R.V., Isaev A.A., Rizvanov A.A.

Kazan (Volga region) Federal University, Kazan, Russia

fairin@mail.ru

Mutations in dysferlin gene lead to dysferlinopathy which is relatively prevalent muscular dystrophy. This disease results in gradual skeletal muscle degeneration primarily in calf muscles in the lower limbs. Two main clinical phenotypes exist: limb girdle muscular dystrophy type 2B and Miyoshi myopathy. There is no effective treatment for these diseases yet exist.

The objective of current study was application of spliceosome-mediated RNA trans-splicing (SMaRT) and CRISPR/Cas9 technologies to correct mutation in DYSF gene. SMaRT allows to reprogram RNA splicing process to substitute a mutant exon with wild type via pre-trans-splicing molecules (PTMs). PTMs are complex molecules consisting of 3 domains: binding domain, targeted to an exon of interest; splicing domain, initiating splicing process on the PTM; and a coding domain, a sequence, coding new exon.

Methods. Extraction and immortalization of patients' skin and gingiva mutant in exon 26 of DYSF gene fibroblasts. Mutant DNA exon in these cells is substituted to a wild type by CRISPR/Cas9 gene editing tool and donor DNA transduction. In additional experimental group, expression of DYSF gene in cells was first activated by CRISPR/Cas9 SAM system for subsequent transduction with AAV2 carrying PTMs.

Results. Changes in DYSF gene and dysferlin gene expression were evaluated by immunofluorescence, western blot analysis and confirmed by next generation sequencing. After dysferlin gene activation fibroblasts were trans-differentiated into myoblasts and myotubes with the following evaluation of DYSF and MyoD expression.

To conclude, both RNA and DNA editing methods were successful. Dysferlin expression levels were detected.

\section{6 \\ COMPARATIVE ANALYSIS OF THE EFFECT OF LOW DOSES OF RADIATION ON HUMAN MESENCHYMAL STEM CELLS}

Usupzhanova Daria, Astrelina T.A., Nikitina V.A., Suchkova Yu.B., Kobzeva I.V., Brunchukov V.A., Brumberg V.A., Nugis V.Yu., Osipov A.N., Samoylov A.S.

State Research Center - Burnasyan Federal Medical Biophysical Center FMBA of Russia, Moscow, Russia usupzhanova94@mail.ru

Objective. Throughout life, a person is constantly exposed to low doses of radiation. However, despite the prevalence and severity of the effects of radiation on the body, to date, its effects on stem cells of humans (regenerative reserve) have not been studied. Thus, the aim of this work was to study the effect of low doses of radiation on mesenchymal stem cells (MSC) from various sources to assess the long-term effects in vitro.

Methods. The cells were cultivated according to the standard methods. The level of surface antigens were evaluated by flow cytometry. And also cytogenetic and morphological methods were applied.

Results. After exposure of MSC mucosal gum tissue at a dose of $80 \mathrm{mGy}$ an increase in the level of proliferative activity, stability of the levels of surface antigens (AG), and a significant decrease in the number of chromosomal aberrations compared with the control group during prolonged cultivation were observed. Following exposure of MSCs of the placenta: the levels of CD73 and CD105 were decreased at doses of 250 and 1,000 mGy in long-term culture, whereas proliferative activity was increased at a dose of 1,000 mGy. Following exposure of MSCs of the corneal limbus: levels of CD73 and CD105 were increased after irradiation at a dose of $80 \mathrm{mGy}$ and the levels of all AG for all doses in long-term culture were increased, except for a decrease in the levels of CD73 at a dose of $80 \mathrm{mGy}$.

Conclusion. The results of our study showed that low doses of radiation exposure affect human MSCs. It was found that the effects of the same dose may be different for MSCs from different types of tissues. The effect can be both depressing, as well as stimulating by the same criteria. The presented research will be continued and supplemented. 


\title{
37
}

\section{BIOCOMPATIBILITY AND OSTEOINDUCTIVE POTENTIAL OF COMPOSITE MATERIALS BASED ON CHITOSAN AND COLLAGEN HYDROGELS IN A RAT MODEL}

\author{
Vasilyev A.V. ${ }^{1,2}$, Kuznetsova V.S. ${ }^{1}$, Bukharova T.B. ${ }^{2}$, Zagoskin Yu.D. ${ }^{3}$, Grigoriev T.E. ${ }^{3}$, Osidak E.O. ${ }^{4}$, E.V. Galitsyna ${ }^{2}$, \\ Babichenko I.I. ${ }^{1}$, Domogatsky S.P. ${ }^{4,5}$, Chvalun S.N. ${ }^{3}$, Goldstein D.V. ${ }^{2}$, Kulakov A.A. ${ }^{1}$ \\ ${ }^{1}$ Central Research Institute of Dental and Maxillofacial Surgery, Moscow, Russia \\ ${ }^{2}$ Research Centre of Medical Genetics, Moscow, Russia \\ ${ }^{3} \mathrm{NRC}$ "Kurchatov Institute", Moscow, Russia \\ 4"IMTEK", Ltd., Moscow, Russia \\ ${ }^{5}$ Federal State Budgetary Institution National Medical Research Radiological Center \\ of the Ministry of Health of the Russian Federation \\ vav-stom@yandex.ru
}

Background. The scaffold for BMP-2 delivery should be biocompatible and provide prolonged release of protein comparable with physiological release rate. Also, it should keep the shape. It could be achieved by thermosetting. Materials based on chitosan and collagen are promising for the creation of such scaffolds.

Objectives. To evaluate the biocompatibility and osteoinductive potential of composite materials based on chitosan and collagen hydrogels impregnated with rhBMP-2 in a rat model.

Materials and methods. Chitosan hydrogel was obtained by dissolving chitosan in acetic acid and then it was dialyzed. An aqueous solution of $\beta$-glycerophosphate was added at $4{ }^{\circ} \mathrm{C}$. A hydrogel was saturated with highly porous polylactide granules with rhBMP-2, which were obtained by freeze-drying method. For the collagen hydrogel preparation, a 10\% neutral solution of pig type I collagen was mixed with sterile rhBMP-2 and human fibronectin in a ratio of 1: 4 . The rhBMP-2 concentration in both materials was $10 \mu \mathrm{g} / \mathrm{ml}$. Both materials formed hydrogel at body temperature $\left(37^{\circ} \mathrm{C}\right)$. Adult male Wistar rats were used in this study. Materials were implanted subcutaneously in the interscapular region. The osteoinductive potential of the materials was evaluated, using a rat calvarial defect model. Animals were euthanized after 7,14 days for assessment of biocompatibility and after 28 days for osteogenesis assessment.

Results. The materials were biocompatible and didn't cause inflammation. When using a chitosan-based hydrogel after 28 days formation of $56 \pm 25 \%$ of bone was observed. Materials based on collagen-fibronectin gel induced osteogenesis and the formation of $78 \pm 18 \%$ of a new bone of total defect volume.

The research was supported by the Russian Science Foundation [grant number 16-15-00298] and RFBR state assignment for Research Centre of Medical Genetics.

\section{8 \\ A RAPID CONTROL PROTOTYPING SYSTEM FOR TESTING PARTIALLY AUTOMATED MECHANICAL VENTILATION}

Von Platen P., Leonhardt S., Walter M.

Medical Information Technology, RWTH Aachen University, Aachen, Germany

platen@hia.rwth-aachen.de

Mechanical ventilation has become a standard treatment method for patients suffering from Acute Respiratory Distress Syndrome (ARDS). Despite often being lifesaving, suboptimal ventilator settings can lead to ventilator-induced lung injury (VILI), which may exacerbate the patient condition. Due to the diversity of patients and illness evolution, finding optimal ventilator settings for individual patients remains a difficult task. To help clinicians in choosing ventilator settings, modern ventilators have started to incorporate automated functions. However, many fail to incorporate the diversity and inhomogeneity of patient illnesses and therefore there is a need for developing an automated personalized mechanical ventilation strategy.

To allow such new algorithms to be tested quickly, a rapid control prototyping system has been designed, which incorporates an intensive care mechanical ventilator, a variety of test lungs, a real-time computer system and a medical PC. Measurement data from the ventilator can be analysed in real-time and ventilator settings can be changed automatically. As such automated processes can be easily tested using real hardware and problems can be detected early. A finite state machine algorithm which allows for automated titration of the positive end-expiratory pressure (PEEP) has been successfully developed and tested using this system. 


\title{
Translational and Personalized Medicine
}

\author{
39 \\ ASSESSMENT OF TOXIC AND ESSENTIAL TRACE ELEMENTS CONTENT IN PARKINSON'S \\ DISEASE PATIENTS \\ Ajsuvakova O.P. ${ }^{1,2}$, Willkommen D. ${ }^{3}$, Tinkov A.A. ${ }^{1,2}$, Skalnaya A.A. ${ }^{4}$, Danilov A.B. ${ }^{1}$, Michalke B. ${ }^{3}$, Skalny A.V. ${ }^{1,2,5}$ \\ ${ }^{1}$ I.M. Sechenov First State Medical University, Moscow, Russia \\ ${ }^{2}$ Yaroslavl State University, Yaroslavl, Russia \\ ${ }^{3}$ Helmholtz Zentrum München, Neuherberg, Germany \\ ${ }^{4}$ Moscow State University, Moscow, Russia \\ ${ }^{5}$ People's Friendship University of Russia, Moscow, Russia \\ oajsuvakova@gmail.com
}

Objective. The existing data show on important role of toxic and essential trace elements in development of Parkinson's disease (PD) through different mechanisms. Therefore, the objective of our study is an assessment of elements' level in hair, serum, and urine of patients with PD.

Methods. The preliminary study involved a total of 30 patients including 15 patients with diagnosed PD and age- and gender-adjusted controls. Total concentration of essential and toxic elements was determined by ICP-MS method. Speciation analysis was performed using HPLC-ICP-MS system.

Results. The significant differences were not found in the total concentration of $\mathrm{Cu}, \mathrm{Fe}, \mathrm{Zn}$, and $\mathrm{Mn}$ in the serum and urine of PD patients and controls. In PD serum $\mathrm{Cd}$ and Pb levels were reduced by 5 and 1.5 fold, respectively, whereas $\mathrm{Hg}$ content was reduced in hair, serum and urine by a factor of more than 2, 5 and 5 in persons with PD in comparison with the control. The obtained data demonstrate that in PD the ceruloplasmin-bound fraction of $\mathrm{Cu}$ is decreased. It is noticed that the fraction of manganese bound to small proteins (possibly metallothioneins) and citrate ions tend to increase in PD patients. Considering that citrate is the predominant Mn ligand in cerebrospinal fluid, it can be proposed that Mn redistribution between ligands with large and small molar masses in PD patients may take place.

Conclusion. The obtained data indicate that despite the absence of differences in the total copper content, speciation analysis revealed differences between the patients and control group.

\section{0 \\ ESTROGEN RECEPTOR $\beta$ ROLE IN TUMOUR SUPPRESSION OF TRIPLE NEGATIVE BREAST CANCER}

Alexandrova E. ${ }^{1,2}$, Saggese P. ${ }^{1}$, Pecoraro G. ${ }^{1}$, Lamberti J. ${ }^{1}$, Giurato G. ${ }^{1}$, Ravo M. ${ }^{1,2}$, Collina F. ${ }^{3}$, Cantile M. ${ }^{3}$, Botti G. ${ }^{3}$, Nassa G. ${ }^{1,4}$, Tarallo R. ${ }^{1,4}$, Rizzo $F^{1}{ }^{1,4}$ and Weisz A. ${ }^{1,4}$

${ }^{1}$ Laboratory of Molecular Medicine and Genomics, Department of Medicine and Surgery, University of Salerno ${ }^{2}$ Genomix4Life Srl, Spin-Off of the Laboratory of Molecular Medicine and Genomics, Department of Medicine and Surgery, University of Salerno, Baronissi (SA), Italy

${ }^{3}$ Pathology Unit, Istituto Nazionale Tumori-IRCCS-Fondazione G. Pascale, Naples, Italy

${ }^{4}$ Division of Molecular Pathology and Medical Genomics, "SS. Giovanni di Dio e Ruggi d'Aragona - Schola

Medica Salernitana" University of Salerno Hospital, Salerno, Italy

Breast cancer (BC) is the most common cancer in women worldwide, and is classified in multiple subtypes, including the so called triple-negative BC (TNBC). This is characterized by lack of estrogen receptor alpha $(\mathrm{ER} \alpha)$, progesterone receptor (PR) and epidermal growth factor receptor 2 (HER2/neu), that represent common targets for BC treatment. Their absence limits the number of therapies that may be applied for TNBC treatment, suggesting the need to identify novel therapeutic targets against this disease. Several studies reported that the beta ER subtype (ER $\beta$ ) is expressed in a sizeable fraction of TNBCs where its presence correlates with improved patient outcome. We evaluated ER $\beta$ expression in TNBC tissues by immunohistochemistry using two validated antibodies, demonstrating presence of this protein in $28 \%$ of samples. To investigate, in this context, the role of this estrogen receptor in TNBC biology, ER $\beta$-expressing cell lines, representing different TNBC subtypes, were generated. Cellular and functional assays confirmed the 
antiproliferative activity of ER $\beta$ in TNBCs. Interaction proteomics revealed in BC nuclei the presence of several protein complexes associated with this receptor involved in chromatin remodeling, miRNA maturation and mRNA transcription. Transcriptome analyses pointed out tumor subtype-specific signaling pathways deregulation. Interestingly, among these the cholesterol biosynthesis pathway was commonly downregulated in all cell lines tested. Global analyses of ER $\beta$ binding to the genome showed its recruitment to regulatory sites of Sterol Regulatory Element-Binding Protein 1 (SREBP1), indicating a direct regulation of this pathway by the receptor.

These findings suggest that drugs targeting components of cholesterol biosynthesis pathway may be new potential therapeutic options for TNBC treatment.

\section{1 \\ THE POSSIBILTY OF A PERSONALIZED APPROACH FOR THE PREVENTION AND TREATMENT OF HERPESVIRUS INFECTION}

Alimbarova L.M., Lazarenko A.A., Barinsky I.F.

FSBE "N.F. Gamaleya Federal Research Centre of Epidemiology and Microbiology" Ministry of Health of Russia, Moscow, Russia, Sechenov First Moscow State Medical University, Moscow, Russia

virology@mail.ru

Herpesvirus infection (HI) is one of the most socially significant human diseases in which therapy is prescribed, as a rule, empirically and is not always accompanied by an adequate result.

Objective. To study a personalized approach to the treatment of HI, providing synergistic use of methods of patient-directed associated therapeutic and diagnostic effects.

Methods. the study included 75 patients aged 20-45 years (male - 52, women - 23) with different clinical forms and severity of $\mathrm{HI}$ and the degree of effectiveness of the therapeutic/prevention activities. To determine the causes of therapy inefficiency, a study of a set of individual characteristics of patients and viral pathogens was carried out. In all patients, the diagnosis of HI was due to HSV, which was confirmed by the detection of specific antibodies to the virus.

Results. Patients infected with HSV-1 or HSV-2 were $62.7 \%$ and $24.0 \%$ respectively; association of pathogens was detected in $13.3 \%$. Prescription of the disease up to 2 years was established in 40 patients, up to 5 years - in 19, up to 10 years and more - in 16 . All patients previously received therapy with acyclic nucleosides: 1 course received $26.7 \%$ of patients, 2 or more courses $-73.3 \%$. Phenotypic analysis of HSV showed that $87.3 \%$ of the strains were sensitive to ACV. The structure of ACV sensitivity was dominated by moderately sensitive strains (55.4\%). The proportion of insensitive strains was $10.7 \%$. Based on the initial results of individually oriented diagnosis and taking into account the spectrum of HSV sensitivity, patients were prescribed personalized therapy, the effectiveness of which was monitored by dynamic assessment of virological status.

Conclusion. The use of a personalized approach to the diagnosis and treatment of $\mathrm{HI}$ is important for the adequate selection of the optimal treatment regimen, improving the economic efficiency of therapy and the quality of life of the patient.

\section{2 \\ ANTIBIOTIC RESISTANCE OF PATHOGENS URINARY TRACT INFECTIONS \\ Beisenayeva A.R., Muldaeva G.M., Garifzyanova E.S., Garifzyanov R.F. \\ Non-commercial joint-stock company "Medical University of Karaganda; Karaganda, Kazakhstan \\ BeysenaevaA@kgmu.kz}

Introduction. Each year, more than 7 million people with symptoms of urinary tract infections (UTI) seek specialized medical care, and about $15 \%$ of all prescribed antibacterial drugs (ABP) are used by a group of fertile-aged patients. The selection of ABP is mainly empirical and should be based on local data on the sensitivity of pathogens to ABP. 
The Aim of the study. determine the spectrum of the main bacterial pathogens of urinary tract infections in women of childbearing age and study the sensitivity of selected pure cultures to antibacterial drugs at the outpatient stage.

Materials and methods. Inclusion criteria were: non-pregnant female patients aged 18 to 49 years with the clinical picture of one of the listed infections: acute cystitis, exacerbation of recurrent cystitis, acute pyelonephritis, exacerbation of chronic pyelonephritis and the release of the pathogen in a diagnostically significant titer. The clinical material for the study was the average portion of the morning freely released urine obtained after the toilet of the genitals. Bacteriological examination of clinical material was carried out by a quantitative method. Determination of the sensitivity of the isolated strains to antimicrobial agents was carried out using disc methods in accordance with the recommendations of the Institute of Clinical and Laboratory Standards (CLSI 2012).

Results. The most frequent causative agents of UTI are E. coli, which was isolated in $62 \%$ of cases and Streptococcus, beta-haem. Group B - 20\%. Of the 32 ABPs, to which the sensitivity of Escherichia coli was tested at $96.15 \%$, the pathogen was sensitive to third-generation cephalosporins (cephtaxime, ceftriaxone), fosfomycin, however, in half of the cases, the microorganism was cefaperan-resistant.

With respect to Streptococcus, beta-haem. Group B conducted a sensitivity study for 16 BPA. Among them, in $90.625 \%$, the pathogen also showed high sensitivity to ceftriaxone, fosfomycin, in $25 \%$ of cases showed resistance to ofloxacin, ciprofloxacin.

Findings. Cephalosporins of the third generation (cephtaxime, ceftriaxone), fosfomycin have high activity against pathogens of uncomplicated UTIs.

\title{
43 \\ OXIDATIVE STRESS AS RISK FACTOR FOR COMPLICATIONS AFTER ABDOMINAL SURGERY IN CARBON DIOXIDE PNEUMOPERITONEUM
}

\author{
Borodina I. ${ }^{1}$, Vlasova I. ${ }^{1}, 2$, Titkova S. ${ }^{3}$, Khusyainova A. ${ }^{4}$, Ivakhov G. ${ }^{4}$, Vakhrusheva T. ${ }^{1}$, Mikhalchik E. ${ }^{1}$ \\ ${ }^{1}$ Federal Research and Clinical Center of Physical-Chemical Medicine, 119435 Moscow, Russia \\ 2I.M. Sechenov First Moscow State Medical University, Institute for Regenerative Medicine, 119991 Moscow, \\ Russia \\ ${ }^{3}$ Department of Experimental Surgery, Pirogov Russian National Research Medical University, Moscow, Russia \\ ${ }^{4}$ Department of Faculty Surgery, Pirogov Russian National Research Medical University, Moscow, Russia \\ lemik2007@yandex.ru
}

Objective. Laparoscopic surgery (LS) for chronic abdominal pathology is a common daily-performed procedure worldwide and continues to increase in use for acute abdominal conditions (ACs). Both open and laparoscopic interventions can enhance oxidative stress (OS) [Sheweita 2014], including effects of $\mathrm{CO}_{2}$ [Vodopija et al 2011]. Decrease in plasma thiols was found in patients who developed postoperative sepsis [Pasechnik 2015].

Methods. Plasma thiols, erythrocytes' glutathione (GSH), glutathione peroxidase activity (GPx), plasma myeloperoxidase concentration (MPO) were evaluated as complications predictors. Blood samples of patients after elective LS for chronic ACs (group 1, n=6), emergency LS for acute uncomplicated ACs (group $2, n=6$ ) and for acute ACs complicated by diffuse peritonitis (group 3, n=4) were studied before surgery ("0"), immediately, in 2 and 48 hours after, and compared with blood of healthy subjects (HS, n=15).

Results. In patients at "0"' erythrocytes showed less GSH and higher GPx than in HS; patients' plasma MPO was raised. Plasma thiol level was lower in group 3. Only in group 1, GSH correlated with GPx $(\mathrm{p}<0.05)$ indicating compensatory response to inflammation while in group 3 an inverse correlation was found. Unexpectedly, MPO in groups 1 and 2 correlated with thiols. Among group 3, MPO concentration changed variously, showing the relatively lower $(5 \mathrm{ng} / \mathrm{ml})$ as well as higher $(2 \mathrm{ug} / \mathrm{ml})$ values compared with the range of 4-90 ng/ml in HS.

Conclusion. The interplay between plasma MPO and blood redox status can be involved in progression of complications after LS.

The research is supported by RSF grant № 17-75-30064. 


\section{4 \\ CLINICAL CHARACTERISTICS OF THE EFFECTIVENESS OF INDIVIDUAL MEANS FOR ORAL HYGIENE WITH DECOMPENSATE FORM OF CARIOUS PROCESS}

Burikh R.I., Phillipova Z.A., Kozhevnikov V.V.

Voronezh NN Burdenko State Medical University, Postgraduate Dentistry Department

rosvrn@gmail.com

Objective. The undoubted interest of practicing dentists causes the possibility of widespread clinical application of modern remineralizing agents, in particular, brushite crystals. This substance has unique adhesive properties and tropicity to crystals of hydroxyapatite surface enamel. The principal mechanism of action of the RemarsGel system is the chemical reaction that occurs when calcium nitrate is mixed from tube No. 1 with ammonium hydrophosphate from tube No. 2, resulting in the formation of a brushite crystal on the surface of the teeth.

Methods. From a clinical point of view, the study is a comparative characteristic of the clinical efficacy of a standard prevention program (with the use of traditional fluorine-containing means of individual oral hygiene) of caries recurrence in the treatment of caries in patients with a high degree of activity of the carious process and the above-mentioned developed program of using RemarsGel. The effectiveness of the applied method was monitored using clinical research methods immediately after restoration and 1, 12 and 36 months after treatment.

Results. Based on the results of the conducted research, high efficiency of brushite crystals was established in terms of prevention of violations of the integrity of the enamel-composite compound at the microchemical level, which has a direct and immediate effect on the quality of the restoration.

Conclusion. These results are confirmed by a complex of highly informative clinical research methods, using an automated approach to the study of the problem.

\section{5 \\ LYSINE OXIDASE EXPOSES A TARGETABLE LIABILITY IN TRIPLE-NEGATIVE BREAST CANCER CELLS BY INDUCING THE ANTIOXIDANT ENZYME THIOREDOXIN REDUCTASE 1 \\ Chepikova Olga ${ }^{1,2}$, Malin Dmitry ${ }^{1}$, Strekalova Elena ${ }^{1}$, Zamyatnin Andrey ${ }^{2}$, Cryns Vincent L. ${ }^{1}$ \\ ${ }^{1}$ University of Wisconsin Carbone Cancer Center, University of Wisconsin-Madison, Madison, WI USA \\ ${ }^{2}$ Institute of Molecular Medicine, Sechenov First Moscow State Medical University, Moscow, Russia \\ chepikovaolga@gmail.com}

Objective. Many tumor cells are highly vulnerable to deficiencies in certain amino acids, which has led to therapeutic strategies to degrade them using amino acid oxidases. Lysine oxidase (LO) degrades lysine and produces hydrogen peroxide, which causes the generation of reactive oxygen species (ROS). Although LO has been reported to have cytotoxic effects against diverse tumor cells, the cell death mechanisms of LO are poorly understood. We postulated that LO activates a number of cellular stress response pathways that can be targeted therapeutically to enhance the antitumor effects of LO.

Methods. Here we investigated the effects of LO against a panel of triple-negative breast cancer (TNBC) cells. To distinguish between its effects on lysine degradation and ROS production, TNBC cells were cultured in control and lysine-free medium. The effects of LO on cancer cell viability, survival and induction of apoptosis were determined. The thioredoxin reductase 1 (TXNDR1) gene was silenced or inhibited to delineate its functional role in sensitizing TNBC cells to LO.

Results. We observed that LO was more cytotoxic than lysine restriction. The cytotoxic activity of LO was at least partly dependent on ROS production since these effects were diminished by N-acetylcysteine (NAC). Moreover, LO activates the alternative cell death pathways necroptosis and ferroptosis, whereas no caspase activation was detected. Immunoblot analysis of TNBC cells treated with LO indicated that NRF2, a key transcriptional regulator of antioxidant genes, was induced within 1 hour of LO treatment. This rapid induction of NRF2 coincided with the induction and increased enzymatic activity of thioredoxin reductase 1 (TXNRD1) 
in response to LO. The combination of auranofin (a TXNRD1 inhibitor used to treat rheumatoid arthritis) and LO resulted in enhanced ROS levels and robust induction of cell death, suggesting a synthetic lethal effect. Intriguingly, NAC attenuated the cell death effects of LO and auranofin, indicating that ROS plays a critical functional role in these effects.

Conclusion. Our findings point to a novel therapeutic strategy whereby LO exposes a synthetic lethal vulnerability of TNBC cells to the TXNRD1 inhibitor auranofin by increasing expression of its molecular target and rendering tumor cells dependent on the thioredoxin pathway for survival.

\section{6}

\section{REMOTE PATIENTS' MONITORING IN ONCOLOGY}

Gogvadze Elena, Scotland Alf, Sprengel Jörg, Metcalfe Thomas, Hofmann Henry

Symsights AG, Basel, Switzerland

elena.gogvadze@symsights.com

The ubiquitous availability of smartphones and the rise of wearables led to the constantly increasing use of digital technologies in disease monitoring and management. Capturing disease symptoms at high frequency and precision in real world environments has an enormous value for physicians and researchers. At the same time, digital technologies provide help and support to patients, allowing them to spend less time in hospitals and more with their family and empowering them to monitor and self-manage disease symptoms from home.

More than 4.2 million new cancer cases occur each year in Europe alone. Common therapies have a wide range of side effects that considerably affect quality of patient's life and could be life-threatening. It was estimated that about $80 \%$ of cancer hospitalization are due to uncontrolled symptoms, which highlights the importance of continuous symptoms monitoring and management. Digital technologies have the potential to considerably improve disease monitoring and cancer patients' experience. However, mobile solutions for oncology represent a small portion of existing applications.

At symsights we are creating a platform for remote monitoring of cancer treatment side effects that will empower patients, support physicians and clinical teams, and generate novel disease insights for research. Our solution uses mobile and web technologies for patients and care teams to provide a more detailed picture about patient's development of side effects, facilitating interaction between patients and physicians, and allowing early intervention to help prevent serious adverse events.

\section{7 \\ APPLICATION OF 3D-TUMOR SPHEROIDS IN DRUG DISCOVERY}

Kaviladze Mariam

Sechenov First Moscow State Medical University, Moscow, Russia

mariam-kaviladze@mail.ru

Introduction. At present, various models are used in experimental oncology, including spontaneous, transplanted, and induced tumors of animals, human tumors transplanted to animals, various cultures of human and animal tumor cells, as well as molecular genetic models. In these latter days special importance is played to in vitro models based on cell cultures, including multicellular tumor spheroids (MTS) because of the tightening of the requirements for animal experiments. MTS are artificially produced small solid tumors, which are a three-dimensional (3D) model consisting of cancer cells received by taking a biopsy from a cancer patient. Three-dimensional cultures of tumor cells overcome the limitations associated with such basic characteristics as volume gradients, growth factors, and metabolites and the presence of necrotic, hypoxic, resting, and proliferating cells. The aim was to prove the advantage of the 3D model over the 2D model in order to further integrate the in vitro model of tumor spheroids into the design of anticancer drugs and to use primary tumor cells in drug screening studies for the implementation of personalized cancer treatment.

Materials and Methods. In the study, multicellular spheroids generated from a suspension of isolated cells of the immortalized adenocarcinoma cell line MCF-7 of human mammary gland were obtained in the 
serum. Microcapsules with MTS were incubated in 24-well plates with Methotrexate for 48 hours. The control group was presented by the monolayer MCF-7 culture $(100,000$ cells per well). Quantitative evaluation of the surviving cells was carried out with trypan blue dye in a Fuchs-Rosenthal counting chamber.

Results. The survival rate of viable cells in the control group was 2 times less than in MTS with a Methotrexate concentration of $100 \mathrm{nM}$. Evaluation of the cytotoxic effect of Methotrexate, based on the size of MTS was also made. When Methotrexate concentration of $100 \mathrm{nM}$, the number of living cells was 65 and $88 \%$ for spheroids with size of 150 and $300 \mu \mathrm{m}$, respectively, while in the control group this value was only $35 \%$.

Conclusion. Compared to monolayer cultures, cancer cells in three-dimensional spheroid cultures demonstrate greater resistance to cytotoxic drugs, with the cytotoxic effect of Methotrexate decreasing while MTS size increasing. In this regard, three-dimensional tumor models are a valuable "tool" for cancer research in the context of drug discovery.

\section{8 \\ DNA METHYLATION-BASED AGE PREDICTION FROM BLOOD: THE LEVEL OF METHYLATION OF 5 CPG MARKERS}

Kipen A.V., Bahdanava M., Burakova A., Dobysh O., Lemesh V.

Institute of Genetics and Cytology of the National Academy of Sciences, Minsk, Belarus

V.Lemesh@igc.by

Background and Objectives. Determining chronological age from biological fluid samples and tissue fragments plays an important role in forensic practice: it can limit the search for identification of remains, narrow the number of suspects, thereby saving time, which is often the limiting factor in the investigation process. Due to the importance of the problem of ensuring the safety of citizens of the Union State (Russian Federation and the Republic of Belarus), the development of age determination technologies for changing lifetime DNA modifications is undoubtedly relevant.

Methods. In this study the methylation level of 5 CpG markers for peripheral blood samples from [1] was analyzed for 150 people of Belarusian nationality using SNaPshot technology - cg14361627 (KLF14 gene, Kruppel like factor 14, NCBI Gene ID - 136259), cg16867657 (ELOVL2 gene, ELOVL fatty acid elongase 2, NCBI Gene ID - 54898), cg16054275 (F5 gene, coagulation factor V, NCBI Gene ID - 2153), cg06784991 (ZYG11A gene, zyg-11 family member A, cell cycle regulator, NCBI Gene ID - 440590), Chr3: 51741152 (GRM2 gene, glutamate metabotropic receptor 2, NCBI Gene ID - 2912).

Results. The lowest methylation level was noted for CpG cg14361627 (KLF14 gene) - $4.74 \pm 2.40 \%$, the highest - for cg16867657 (ELOVL2 gene) $-54.83 \pm 14.02 \%$. The widest range of values obtained is noted for cg16867657 (ELOVL2 gene) - 27.80-80.00\%. The highest correlation coefficient (R) characterizing the CpG potential for solving the problem of determining the chronological age by DNA methylation level was shown for CpG cg14361627 (KLF14 gene) - 0.570 ( $\mathrm{p}=0.0002)$, then, in order of decreasing R, CpG markers cg06784991 (ZYG11A gene) - 0.529 ( $\mathrm{p}<0.0001)$ and cg16867657 (ELOVL2 gene) - 0.521 ( $\mathrm{p}=0.0129)$. For CpG markers cg16054275 (F5 gene) and Chr3: 51741152 (GRM2 gene), statistically significant associations between the methylation level and chronological age were not found. The results obtained will be used to construct a regression model for determining the chronological age of an individual in blood samples.
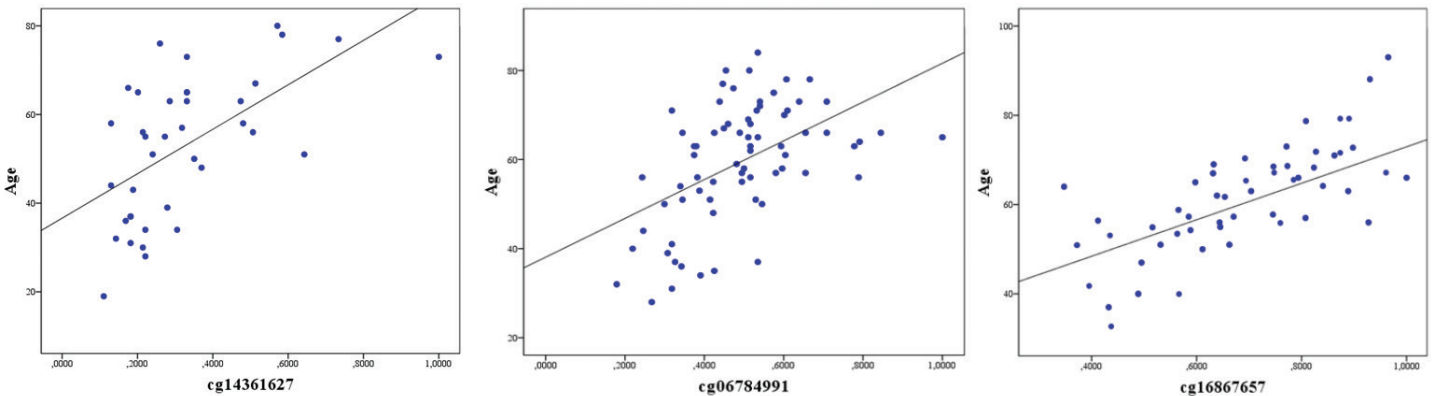

Fig. 1. A plot of the age of a standardized level of DNA methylation. 
Conclusions. The study was realized within the framework of the Union State Scientific and Technical Program "Development of innovative genogeographical and genomic technologies for identifying individuals and individual human characteristics based on studying gene pools of Union State regions" ("DNA Identification"), Activity No 2 "Development of a method for determining the probable age of an individual characteristic of its DNA" (Minsk, Republic of Belarus).

\section{Reference:}

[1] Naue J. [et al.] Chronological age prediction based on DNA methylation: Massive parallel sequencing and random forest regression / Forensic Sci. Int. Genet. 2017. 31. P. 19-28. DOI: 10.1016/j.fsigen.2017.07.015

\section{9 \\ SURVIVAL OF PATIENTS WITH BREAST CANCER ACCORDING TO THE STATUS OF POLYMORPHISM rs1065852 (CYP2D6 GENE)}

Kipen V.N. ${ }^{1}$, Snytkov E.V. ${ }^{2}$, Melnov S.B. ${ }^{2}$

${ }^{1}$ The Institute of Genetics and Cytology of The National Academy of Sciences of Belarus, Minsk, Belarus

${ }^{2}$ International Sakharov Environmental Institute of Belarusian State University, Minsk, Belarus

v.kipen@igc.by

Background and Objectives. The pathological genotype (which increases the risk of the formation of a malignant neoplasm) affects the aggressiveness of tumor growth and, as a result, decreases the survival rate of carriers.

We analyzed the relationship between the carriage of the risk-related genotype on rs1065852 polymorphism (CYP2D6 gene) and a decrease in the survival rate of patients with breast cancer.

A retrospective analysis of outpatient cards, performed with the support of the staff of the State Institution "N.N. Alexandrov Republican Scientific and Practical Center of Oncology and Medical Radiology", allowed to find out the outcome of the disease for $85.8 \%$ of patients $(145 / 169)$ [Kipen V.N. 2017] from the main study group (Belarusian Cancer Registry) 31.0\% (45/145) patients died from the underlying disease (ICD10, C50 - Malignant neoplasm of the mammary gland), 69.0\% (100/145) are alive. Sampling of biological material from patients with breast cancer was carried out in the period 2006-2008. Thus, we had the opportunity to assess the 10-year survival rate.

Methods. Comparison of the frequency of prevalence of genotypes was performed using $\chi$-square (Fisher's exact two-sided test). Survival analysis was performed using Kaplan-Meier curves (Kaplan-Meier estimate).

Results. The analysis ( $\chi$-square, Fisher's exact two-sided test) showed that $88.9 \%(40 / 45)$ of patients with sporadic breast cancer who have the CC/CT genotype for rs1065852 polymorphism (CYP2D6 gene) died from the underlying disease. For patients with the TT genotype, death from the underlying disease was noted only for $11.1 \%$ (5/45). The prevalence of the TT genotype among living patients was 29.0\% (29/100).

A survival analysis using the Kaplan-Meier curves (Kaplan-Meier estimator) also confirmed the findings, the Log Rank (Mantel Cox) $\mathrm{p}=0.027$ (figure 1).

Conclusions. Polymorphism rs1065852 (CYP2D6 gene) is associated with reduced survival of patients with breast cancer. In a first approximation, the histological type of the tumor and the stage of the disease were not related to the prevalence of genotypes for polymorphism rs1065852 (CYP2D6 gene) among patients with breast cancer.

\section{Reference:}

[1] Kipen V.N. The role of low-penetrance alleles in predisposing the development of sporadic breast cancer / Russian Journal of Genetics. 2017. Vol. 53(7). pp. 804-808. DOI: 10.1134/S1022795417070055 


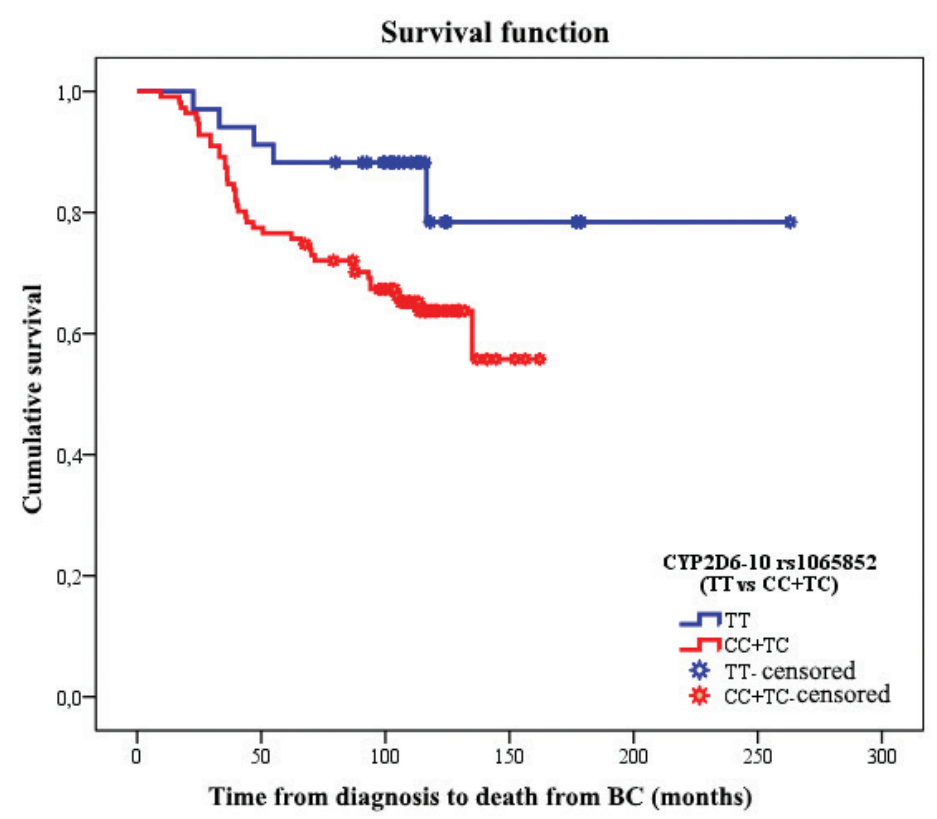

Fig. 1. The Kaplan-Meier curves (Kaplan-Meier estimator), the Log Rank (Mantel Cox) p = 0.027 .

\section{0 \\ ABNORMALITIES OF OLIGODENDROCYTE CLUSTERS IN SUPRA- AND INFRAGRANULAR LAYERS OF THE PREFRONTAL CORTEX IN SCHIZOPHRENIA}

Kolomeets N.S. ${ }^{*}$, Vostrikov V.M.

Laboratory of Clinical Neuropathology, Mental Health Research Centre, Moscow, Russia

nkolomee@mail.ru

Background and Objectives. Deficit of cortical gray matter myelination in the frontal lobes tightly linked with cognitive impairments has been reported in schizophrenia in neuroimaging studies. Oligodendrocyte progenitors proliferate in the adult human brain and form oligodendrocyte clusters (OlC) for functionaldependent adaptive myelination. Reduced myelination may be associated with the deficit of oligodendrocytes (Ol) and OlC. We estimated the numerical density of Ol (NvOl) and OlC (NvOlC) in supra- and infragranular layers of the prefrontal cortex (PFC) in schizophrenia and healthy controls.

Methods. Nissl-stained sections from the schizophrenia subjects $(n=17)$ and healthy matched controls $(n=20)$ were examined. The $\mathrm{NvOl}$ and of OlC were estimated in sublayers 3a- 3c and 5a by stereological optical disector method.

Results. The NvOl and NvOlC were significantly decreased ( $30-50 \%)$ in all sublayers of the PFC in the schizophrenia group as compared to controls. The NvOlC/NvOl ratio decreased significantly in the schizophrenia group in sublayers $3 \mathrm{a}(\mathrm{p}=0.015)$ and $5 \mathrm{a}(\mathrm{p}<0.001)$, but not in sublayers $3 \mathrm{~b}$ and $3 \mathrm{c}$ as compared to controls. In the control group the NvOlC was positively correlated with the NvOl $(R \geq 0.59 ; p \leq 0.006)$ in sublayers $3 \mathrm{~b}, 3 \mathrm{c}$ and $5 \mathrm{a}$. In the schizophrenia group a significant correlation between the parameters $(\mathrm{R}=0.8$; $\mathrm{p}=0.00001$ ) was found only in sublayer $5 \mathrm{a}$.

Conclusions. The deficit of OlC might be associated with altered proliferation and/or maturation of oligodendrocyte progenitors in schizophrenia. Alterations of the NvOlC/NvOl ratio might be due to different connectivity of supra- and infragranular sublayers and their disturbances in schizophrenia. 
51

\section{EVALUATION OF THE MICROSTRUCTURE OF ZIRCONIUM DIOXIDE IN ITS PROCESSING BY VARIOUS TYPES OF DIAMOND BURS}

Krukova S.N., Stanislavchuk E.S.

Voronezh NN Burdenko State Medical University

rosvrn@gmail.com

Objective. Today, zirconium dioxide has opened up new perspectives in modern dentistry, in particular, in fixed prosthetics. Zircon stabilized in tetragonal modification is the most high-performance one. This material has a complex of properties: biocompatibility, chemical stability, high strength and hardness, low thermal conductivity, high light transmission, lightness, aesthetics. Also, zirconium dioxide has hypoallergenic properties, does not cause signs of incompatibility in the oral cavity, does not participate in electroplating processes, and passes x-rays. In orthopedic dentistry, tetragonal polycrystalline zircon, partially stabilized with yttrium, is used. But, when machining the synthesized zircon, there is the problem of preserving the structure and properties of the source material.

Methods. The purpose of this work is to study the mechanical effect on the structure of the studied samples made in a dental laboratory based on met stable tetragonal zirconium t-ZrO2 using the method of scanning electron microscopy.

Results. From the results of the study, it follows that the morphology of ceramic samples based on $\mathrm{ZrO} 2$ varies during mechanical action and depends on the type of boron used and the frequency of its use. Thus, solid diamond burs remain efficient even after their 5 applications, burs with composite fixation of abrasive to 5 applications remain relatively efficient, and burs with galvanoplastic fixation of abrasive to 5 applications come into complete disrepair.

Conclusion. Practical interpretation of the obtained experimental results is undoubtedly essential for developing recommendations on the technology for machining ceramic structures based on zirconium dioxide in a clinical setting and in a dental laboratory.

\section{2}

\section{DYNAMICS OF HEALTH OF PUPILS OF SECONDARY SCHOOLS}

Kuchina A.I., Panina O.A.

Federal State Budgetary Educational Institution of Higher Education "Voronezh State Medical University. N.N. Burdenko" of the Ministry of Health of the Russian Federation media01@list.ru

To analyze the features of the formation of deviations in the health status of younger students. Determine the volume and direction of health-saving technologies.

As a result of the study, it was found that the burden of risk factors (defined as the number of factors per child) significantly increased in the learning process from 5.7 to $8.3(\mathrm{p}<0.05)$. The age of $75 \%$ of mothers to the birth of a child ranged from 24 to 29 years. The presence of chronic diseases in their own at the time of the birth of children was noted by $34 \%$ of women, $5.2 \%$ of mothers had occupational hazards during pregnancy. Toxicosis of the first half of pregnancy was noted in 57\% of women, in 38\% - toxicosis of the first and second half of pregnancy. $84.7 \%$ of children were born full-term, $7.9 \%$ were premature, $3.6 \%$ of newborns had asphyxia during childbirth or other complications.

The impact on the health of primary school students of a large number of adverse factors caused by lifestyle. First of all it concerns the mode and nature of power.

The nature and diet of children in a large number of cases does not meet the hygienic requirements for children of this age group. Of particular importance for health status is the frequency of hot meals. However, only $1 / 4$ children get hot meals $3-4$ times a day, $71 \%$ of schoolchildren -2 times, and the rest - only 
1 time a day. Schoolchildren's dietary inadequacies include meat and dairy products, as well as fresh vegetables and fruits. It was found that $70 \%$ of children consume meat products daily, milk and dairy products (cottage cheese, kefir, yogurt) - 67\%.

Of great importance for the health of the developing organism is physical activity, especially active outdoor games. According to the results of the survey, it was found that in $51 \%$ of schoolchildren the level of the necessary physical activity meets hygienic requirements. About $32 \%$ of children are engaged in physical education only at school lessons in physical education. Only $31 \%$ of pupils do morning hygiene exercises every day, and only $2 \%$ of children share with parents. In the dynamics of learning (from grade 1 to grade 4 ), the proportion of students leading a physically active lifestyle decreases, and the number of children attending additional out-of-school activities with prevailing static loads (circles but interests) increases from $20 \%$ to $47 \%(\mathrm{p}<0,05)$. A sufficient duration of walks in the fresh air on school days is observed in only $9 \%$ of children, which indicates the irrational organization of their leisure time by parents and confirms the low physical activity of children.

The prevalence of extracurricular activities indicates that students are overloaded with various activities. It is obvious that the organization of additional classes proceeds spontaneously, is not regulated by anyone, which, taking into account the peculiarities of this age, cannot but have consequences for the health and functional state of the body of children. These exercises lead to fatigue and contribute to the development of chronic pathology.

Analyzing the social status of families, it was noted that the majority of these families were complete (81\%), the income of $74 \%$ of families was above the subsistence minimum, and $2 \%$ had less than the average. Living conditions in most cases were well-off - $91 \%$ of respondents live in separate comfortable apartments. The average number of rooms per family is 2.2 , while $52 \%$ of students have their own equipped room. When assessing the psychological climate in a family, the relationship as "prosperous" was assessed by $89 \%$ of respondents.

The educational level of parents is quite high - $77 \%$ have a higher professional education, $2 \%$ do not have a professional education. Smoking is a big problem of the modern person and the whole society. The study showed a significant prevalence of smoking among parents of primary school children: one parent smokes in $42 \%$ of children, in $5 \%$ of cases both parents smoke. At the same time, $18 \%$ of parents admitted that they smoke in the presence of a child. It is known that in order for an organism to form normally, the right amount of oxygen and nutrients must be supplied to its cells. Ophthalmologists suggest that smoking increases intraocular pressure. Which leads to partial loss of vision. The effects of smoking leads to hearing loss, metabolic disorders. Smoking slows down the absorption of vitamins and nutrients in the body, which inhibits the development of the child and growth. Scientists have shown that the child's body is particularly sensitive to passive smoking - and the younger he is, the more negatively tobacco smoke affects him.

According to Russian scientists, almost half of all children are doomed to suffer from adult smoking. In addition, it has been proven that passive smoking not only harms children's health, but also contributes to the initiation of smoking from a physiological and psychological point of view. $58 \%$ of children have a lack of sleep at night, only $9 \%$ of children in grade 1 and $1.5 \%$ of children sleep during the day in grade 4 have daytime sleep. Every day, $46 \%$ of students spend 3 hours or more on watching television, and $7 \%$ of them spend 4 to 5 hours each. Every second child spends 2 hours a day at the computer, 19\% - from 2 to 3 hours. In addition, in $74 \%$ of children the time allotted for the preparation of homework exceeds the existing standards, and $15 \%$ spend 5-6 hours on this.

Primary schoolchildren have a significant prevalence of such factors as a lack of night sleep, physical inactivity, irrational organization of leisure and nutrition deficient in the main ingredients. Revealed a high percentage of passive smoking among children. The presence of adverse factors in primary school age leads to stress adaptation mechanisms and reduce the functional capabilities of the body, which increases the risk of the formation of chronic pathology in children.

In this regard, the development of preventive programs for the formation of stereotypes of a healthy lifestyle, where students acquire theoretical and practical knowledge on the promotion and preservation of health, is of great importance. 


\section{3 \\ GENETIC POLYMORPHISM OF GENES ASSOCIATED WITH DYSFUNCTION OF ADIPOSE TISSUE IN ADOLESCENTS RESIDING IN THE ORENBURG REGION}

Lebedeva E.N., Setko N.P.

Orenburg State Medical University, Orenburg, Russia

lebedeva.e.n@mail.ru

Background. The level of obesity among schoolchildren in Russia is growing and now amounts to 5-8\% (in the 90 s this figure was at the level of 2-3\%). According to epidemiological studies, overweight is detected in $10-15 \%$ of children under 7 years of age and $16-26 \%$ of adolescents. Childhood obesity persists as they grow older and progresses. The Orenburg region goes to 10 regions of Russia with a high incidence of obesity.

The purpose is to study the frequency of occurrence of polymorphisms in children residing in the Orenburg region

Methods. Depending on BMI, two groups of adolescents are formed: the 1st group consisted of adolescents with optimal nutritional status (BMI $\leq 25)$; Group 2 - with excessive alimentary status (BMI> 25). In adolescents of both groups, polymorphisms FTO (rs9939609), PPARA (rs4253778), PPARG2 (rs1801282), ADRB2 rs1042713 , ADRB2 (rs1042714) were studied.

The study of polymorphic variants of the studied genes was carried out by the method of allele-specific hybridization in the format of a polymerase chain reaction (PCR) with fluorescent detection in real time (TaqMan) using primer sets (NPO Syntol, Russia) on a DTlite amplificator (DNA-Tekhnologiya, Russia ).

The frequencies of occurrence of alleles and genotypes of 5 SNP were obtained. The allele frequencies (MAF - Minor Allele Frequency) in the subjects of group 2 were as follows: rs9939609 A>T 0,619, rs4253778 $(G>C) 0,882$, rs1801282 (G>C) 0,981, rs1042713 (G>A) 0.882; rs1042714 (G > C ) 0.850; which is significantly more than in group 1.

In conclusion, it should be noted that the frequency of occurrence of genes for susceptibility to the development of metabolic diseases is well studied in Europeans, and in the inhabitants of Central Asia they are poorly studied. Also, the frequency of occurrence of allelic variants of a gene may depend on race and ethnicity. The determination of the frequency of occurrence of candidate gene alleles made it possible to select significant polymorphisms for the child population of the polyethnic region - the Orenburg region for their further case-control study. Research in this direction is ongoing; genotyping of these polymorphisms is carried out on a larger number of samples. For the first time, data were obtained on the distribution of gene polymorphisms associated with obesity in the children's population of the Orenburg region.

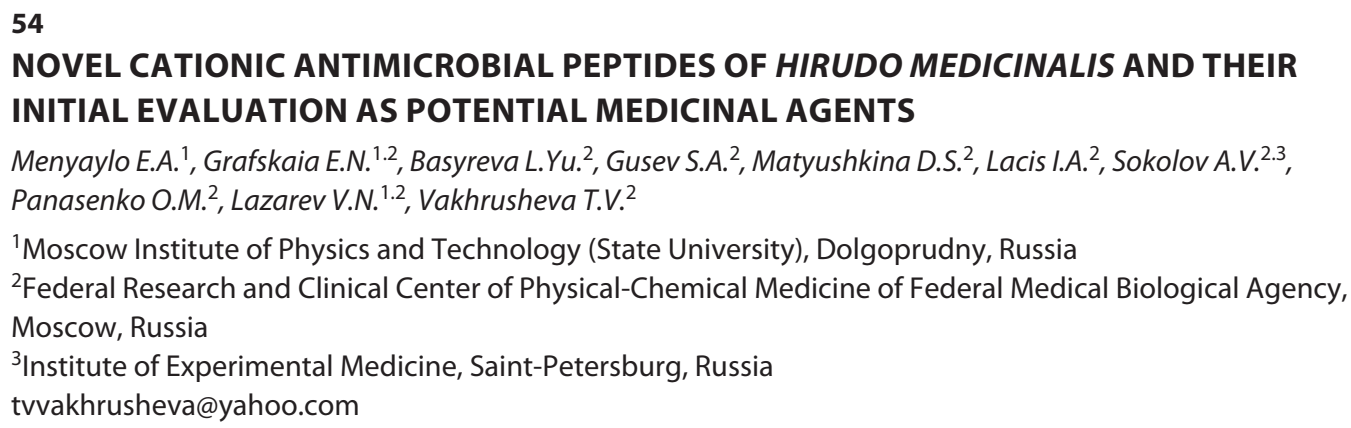

Objective. Cationic antimicrobial peptides (AMPs) are considered as potential candidate drugs against antibiotic-resistant pathogens. Our previous study based on bioinformatic analysis of the Hirudo medicinalis genome allowed synthesis of new AMPs. Considering that AMPs at sites of infection will be faced with activated neutrophils, the present study aims at revealing their mutual influence.

Methods. Measurement of neutrophil extracellular traps (NETs) by blood smear technique, MALDImass-spectrometry, taurine chloramine assay. 
Results. Peptides FRIMRILRVLK (P1), KFKKVIWKSFL (P2) and RWRLVCFLCRRKKV (P3) were under study. The number of NETs in human blood incubated $(3 \mathrm{~h})$ with P3 $(100 \mu \mathrm{M})$ increased 1.7-fold compared to control, with a decrease in leukocyte number by 30\%, whereas no significant changes were found for P1 and P2. For isolated neutrophils incubated (1 h, 10\% autologous serum) with P2 (90 mM) or P3 (20 mM) at their minimum inhibitory concentrations, total cell number decreased (by $70 \%$ and 40\%, respectively) compared to control, with an increased proportion of dead cells. Cell viability in P1-treated suspension was similar to that of control cells. Activated neutrophils secrete myeloperoxidase capable of producing $\mathrm{HOCl}$. MALDI-TOF analysis of HOCl-treated peptides showed the formation of oxygenated and chlorinated products, with P3 being least HOCl-resistant. On the other hand, in the presence of P3, myeloperoxidase produced $\mathrm{HOCl}$ at a faster rate.

Conclusion. The results suggest that P1 may be suitable for further tuning of structure to increase its stability and minimize negative effects on neutrophils.

This work was supported by RFBR grant № 17-75-20099.

\title{
55 \\ CANCER BIOMARKERS IN TRANSLATIONAL APPLICATION AND TARGETED DRUG DELIVERY: PROTEOMICS AND COMPUTATIONAL BIOLOGY APPROACHES
}

\author{
Moldogazieva N.T. ${ }^{1}$, Porozov Yu.B. ${ }^{1,2}$, Ostroverkhova D.S. ${ }^{1}$, Mel'nokova T.I. ${ }^{1}$ \\ ${ }^{1}$ Laboratory of Bioinformatics, Institute of Translational Medicine and Biotechnology, I.M. Sechenov First \\ Moscow State Medical University, Moscow, Russia \\ ${ }^{2}$ Saint Petersburg National Research University of Information Technologies, Mechanics and Optics, \\ St Petersburg, Russia \\ nmoldogazieva@mail.ru
}

Objectives. Cancer biomarker development is aimed on early cancer diagnosis, prognosis, evaluation of anti-cancer drug efficacy and patient's care decision making. To meet translational medicine requirements, it is necessary to develop predictive and pharmacodynamic biomarkers that give precise information about tumor stage and patient's response to a given intervention and drug. Additional challenge is developing safety biomarkers to allow assessing drug toxicity in any tissue.

Methods. Various genomic, epigenomic, proteomic and systems biology approaches along with computational and bioinformatics tools are currently being exploited to discover novel biomarkers.

Results. With the use of bioinformatics tools, the presence of common short linear motifs (SLiMs) in different embryo/placental and cancer-associated proteins has been revealed to elucidate their common functions. Since tumor-specific proteins exert their effects through receptor-mediated mechanisms, they can be used for drug delivery to target cells and tissues to alter cell signaling, immune or inflammatory, proangiogenic response etc.

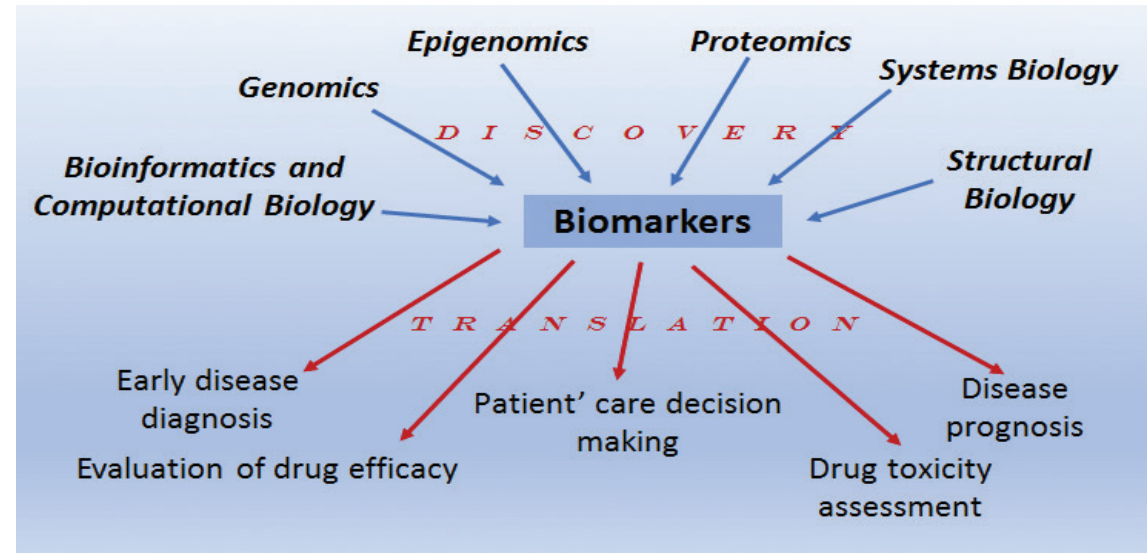

Fig. 1. Biomarker discovery in the context of translational medicine. 
In addition to conventional biomarkers including AFP, DCP, and AFP-L3 used for monitoring treatment responsiveness and tumor recurrence, alpha-L-fucosidase, glypican-3, squamous cell carcinoma antigen-1 (SCCA-1), osteopontin, Golgi protein-73, CEA, VEGF and MMP-2 and MMP-9 along with micro-RNAs are presently being extensively studied as novel molecular biomarkers for HCC.

Conclusion. Integrative proteomic, translational and computational biology approaches are especially useful in case of heterogenous tumors such as HCC.

\title{
56 \\ NOVEL ANTI-PLATELET AGENTS: MOLECULAR DESIGN, ASCERTAINMENT OF THE PROPERTIES REQUIRED FOR A REMEDY PROTOTYPE
}

\author{
Murina M.A. ${ }^{1}$, Roshchupkin D.I. ${ }^{2,1}$, Buravleva K.V. ${ }^{1}$, Sergienko V.I. ${ }^{1}$ \\ ${ }^{1}$ Federal Research and Clinical Centre of Physical-Chemical Medicine of Federal Medical Biological Agency, \\ Moscow, Russia \\ ${ }^{2}$ The Russian National Research Medical University named after N.I. Pirogov (RNRMU), Moscow, Russia \\ marina_murina@mail.ru
}

Objective. The important role of chemical modifications of molecular targets in the therapeutic action of many drug substances, called covalent inhibitors, is finally established. We have discovered a new class of covalent inhibitors of platelet functions. These are chloramine derivatives of taurine and amino acids.

Methods. A quantum mechanical nonparametric method was used to compute the molecular characteristics of the known chloramine compounds and new structural analogues of taurine chloramine. Rate constants for the reactions between sulfur-containing compounds and the chloramines studied were determined with UV-spectrophotometry. Platelet aggregation was induced with ADP and measured with whole blood aggregometer.

Results: With usage of ab initio method of quantum mechanics, it has been developed computational technology for property analysis of n-chlorotaurine structural analogues. Several computational characteristics for constructed platelet inhibitors were founded, which ensure the effective prognostic evaluation of the properties concerning their stability and chemical reactivity. The main characteristics are partial charges for definite carbon atoms and active chlorine in reactive chemical center. The new analogues of n-chlorotaurine have been selected for their chemical synthesis and specific pharmacologic activity testing. Chemical reactivity of the novel potential platelet inhibitors was studied. Knowledge of this property is necessary to develop the platelet inhibitors that possess demanded efficacy, in particular, on an action selectivity on platelets. It was shown that the synthesized n-chlorotaurine analogues react effectively with sulfur-containing atomic groups.

Conclusion. New structural analogues of taurine chloramine possess anti-platelet activity and chemoselectivity with respect to sulfur-containing groups in receptors on the platelet plasma membrane.

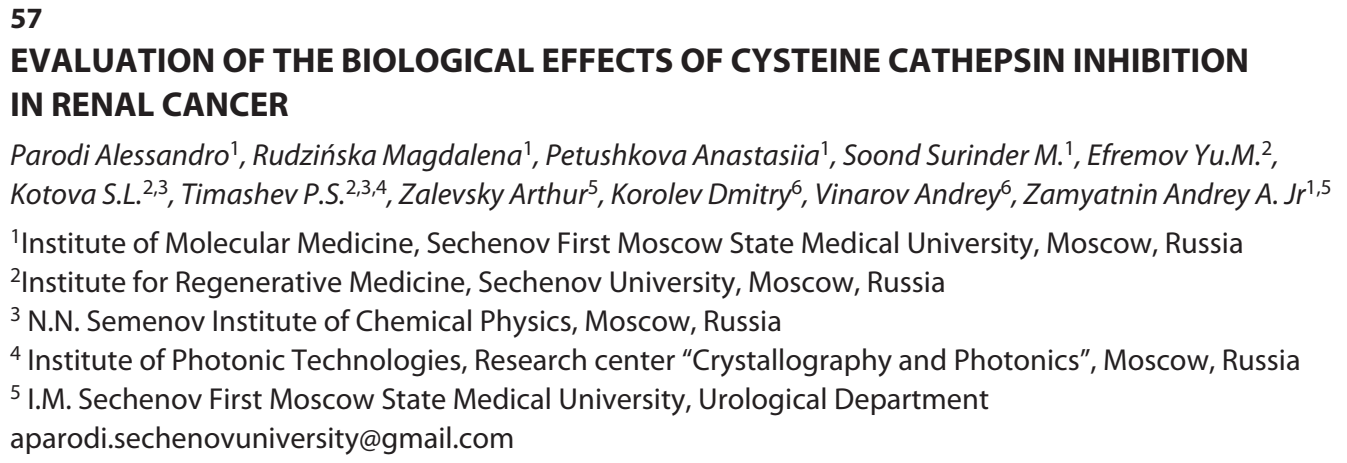

Parodi Alessandro ${ }^{1}$, Rudzińska Magdalena ${ }^{1}$, Petushkova Anastasiia' ${ }^{1}$, Soond Surinder M. ${ }^{1}$, Efremov Yu.M. ${ }^{2}$, Kotova S.L. ${ }^{2,3}$, Timashev P.S. ${ }^{2,3,4}$, Zalevsky Arthur ${ }^{5}$, Korolev Dmitry ${ }^{6}$, Vinarov Andrey ${ }^{6}$, Zamyatnin Andrey A. Jr ${ }^{1,5}$

${ }^{1}$ Institute of Molecular Medicine, Sechenov First Moscow State Medical University, Moscow, Russia

${ }^{2}$ Institute for Regenerative Medicine, Sechenov University, Moscow, Russia

${ }^{3}$ N.N. Semenov Institute of Chemical Physics, Moscow, Russia

${ }^{4}$ Institute of Photonic Technologies, Research center "Crystallography and Photonics", Moscow, Russia

${ }^{5}$ I.M. Sechenov First Moscow State Medical University, Urological Department

aparodi.sechenovuniversity@gmail.com

Introduction. Cystein Cathepsins (Cts) are lysosomal proteases involved in protein degradation, turnover, and cell metabolism. Their overexpression in cancer disease is associated with high aggressiveness and poor outcome of the patients. Due to their high redundancy (there are 11 different Cts) and complex 
regulation of expression and activity, current literature failed in completely determining their role in cancer disease. In this work, we aim to understand the regulation of this group of proteins by following the expression of 2 proteases (Cts B and V) with demonstrated involvement in cancer disease and shed light on their role in favoring or mitigating cancer infiltration. To this goal, we generated 2 peptide inhibitors, named Inh1 and Inh2 with high specificity toward Cts to evaluate cancer cell response to a generalized Cts activity inhibition. This work is particularly important to find new molecular targets for tumors like renal cancer, that being unresponsive to traditional cytostatic agents, they are successfully treated with drugs targeting cell metabolism (i.e. mTOR and tyrosine kinease receptor inhibitors) and eventually endolysosomal biology.

Methods. Active recombinant Cts B and V were expressed in E. Coli and purified via His-Tag procedure. In silico modelling of peptide docking in the active sites of the Cts and fluorescent enzymatic assays were used to demonstrate the inhibitory activity of the peptides. MTT was used to evaluate the cytotoxic effects of the peptides in vitro on the human renal cancer cell line 769-p. The ability of the peptides to inhibit Cts activity in the cells was tested through microscopy analysis, while Cts expression in the presence of the inhibitors was evaluated via RT-PCR and Western blotting. Finally, the effect of the peptides on renal cancer aggressiveness was evaluated through migration assay and corroborated via AFM microscopy measuring cell stiffness.

Results. 3 active Cts (B and V) were successfully generated in engineered E. Coli and their activity was inhibited with both the inhibitors with Inh1 showing a higher inhibition activity than Inh2. Similar evidence was corroborated by the docking models and in vitro directly on renal cancer cells. The peptides showed to slightly decrease $769 \mathrm{p}$ proliferation in particular in the first 48 hours of treatment, while they differentially modulated the mRNA and the protein expression of Cts B and V. In particular after an initial increase, Cts protein expression decrease significantly at 72 hours. Finally, the inhibitors demonstrated significant effects on increasing cell stiffness and modulating cell migration and, also in this case, Inh1 had a stronger inhibitory effect that inh2.

Conclusions and future direction. The generated peptides showed a pronounced inhibitory activity towards the tested Cts with Inh1 consistently showing higher inhibition properties than Inh2. In the cells, they can affect Cts expression and preliminary data on cancer cell biology indicate that these inhibitors may decrease cancer cell spreading. More investigation is necessary to understand the molecular mechanisms standing at the base of the differential Cts expression induced overtime by the inhibitors as well as in vivo evaluation of the effects that these peptides can potentially have on renal cancer cell proliferation and spreading.

\section{8 \\ THE EFFECTIVENESS OF A PERSONAL APPROACH TO LEARNING MANUAL SKILLS AT PREPARING DENTAL HARD TISSUES}

Rostovtsev Vladimir, Shumilovich Bogdan

Voronezh NN Burdenko State Medical University, Voronezh, Russia

rosvrn@gmail.com

The development of practical skills using simulation training provides a personalized approach to learning and objective control of the quality of its execution.

Methods. The 1 phase was included 82 students, divided into a control group where the training was conducted with the use of standard phantoms and group study which used a dental simulator of $V$ generation. Material 2 stages presented 48 young professionals in 2016 who participated in phase 1 . An objective assessment of the quality of preparation made with a scanner Zirkozahn arti s600.

Results. In the control group, the main reason for the need for additional correction of the abutment teeth as 1 and 2 is the inadequacy of stage periodontal ledge factor ANOVA with the indicator 1.1 for one phase of the study and 1.15 for 2 stages, indicating that the statistical predictors in this group identity. The group studies found no statistically significant difference in the quality of the executed periodontal ledges 1 and 2 stages of the study, 0.9-way ANOVA factor, which indicates the statistical significance of the predictor as pre-acquisition movements automatism acquired while working with the simulator.

Conclusion. The use of an interactive computer simulation provides a higher level of acquisition, and the main "survival" of practical skills, confirmed by subsequent clinical practice, compared with the classical form of education. 


\section{9 \\ DIFFERENCES IN PLATELET ENZYMATIC ACTIVITIES IN PATIENTS WITH ENDOGENOUS PSYCHOSES AND ITS RELATION TO EFFECTIVENESS OF ANTIPSYCHOTIC THERAPY}

Savushkina O.K., Prokhorova T.A., Tereshkina E.B., Boksha I.S., Vorobyeva E.A., Lavrova E.A., Samorodov A.V., Pomytkin A.N., Kaleda V.G., Burbaeva G.Sh.

Mental Health Research Centre, Moscow, Russia

Bauman Moscow State Technical University, Moscow, Russia

boksha_irina@mail.ru

Background. Patients with endogenous psychoses represent a heterogeneous group with varying response to antipsychotic treatment. Predicting the individual response to therapy of these patients is a topic task. It is important to know whether biochemical parameters such as activities of platelet enzymes are useful in solving the task.

Goal. Search for correlations between activities of platelet cytochrome $c$ oxidase (COX), glutamate dehydrogenase (GDH), glutathione reductase (GR), and glutathione-S-transferase (GST) and the disease type and response to antipsychotic therapy in patients with endogenous psychoses, and search for link between these activities and psychopathological assessments.

Methods. Activities of platelet enzymes and PANSS scores in patients (men) with schizophrenia (SCH, $n=63$ ) or schizoaffective disorder (SZA, $n=31$ ) were assessed before and after the treatment course with antipsychotics. The "responder" category was attributed to those patients who had not less than 30\% reduction in PANSS score. The activities were also measured in matched control group (men, $n=42$ ). All participants (cases) were clusterized by signs (enzymatic activities) using k-means clustering method and Euclidean distance.

Results. Clustering of all participants (10 iterations, stable solution after third iteration) resulted in three clusters: C1 is represented by controls (18), patients with SCH (17, mainly non-responders), and patients with SZA - (14, mainly responders) having high COX and GDH activities; C2 is mainly represented by controls (20) and two patients with SZA (both are responders) with high GR and GST activities; C3 consists mainly of non-responders patients with relatively low activity of all enzymes.

Conclusion. Enzymatic activities are objectively related to diagnosis and condition of patients evaluated by PANSS, and the use of 4 biochemical signs allows to identify subgroups of responders.

\section{0 \\ MURINE LNCRNA LL35 AS A PROBABLE HOMOLOG OF HUMAN LNCRNA DEANR1 REGULATES MITOCHONDRIAL FUNCTION IN THE CELL}

Sergeeva O., Korinfskaya S., Kurochkin I., Zatsepin T.

Skolkovo Institute of Science and Technology (Skoltech), Moscow, Russia

o.sergeeva@skoltech.ru

Non-coding RNAs (ncRNA) play a significant role in the regulation of many cellular processes, including transcription, translation and cell differentiation. There are examples of ncRNA participation in the development of various diseases (C. Lin and L. Yang, Trends Cell. Biol. 2017), that allows to consider some ncRNAs as potential targets for therapy and diagnostics. It was demonstrated previously that DEANR1 ncRNA participates in the regulation of endoderm differentiation in human embryonic stem cells by cisregulation of the Foxa2 transcription factor (W. Jiang et al., 2015). Foxa2 protein plays an important role in the glucose homeostasis in the liver, affects fatty acids catabolism under the stress conditions and regulates the biogenesis of highdensity lipoproteins (M. Kanaki et al, 2017). Also DEANR1 influences on the epithelialmesenchymal cell transition, which occurs not only during embryonic development but also in fibrosis and during progression of cancer tumors (Y. Fan et al, 2016). We found a potential analogue of the ncRNA DEANR1 in mouse LL35 ncRNA by bioinformatics. We demonstrated LL35 expression in the mouse cell lines and liver with preferable localization in cell nucleus. Also ncRNA changed its amount in liver regeneration and liver fibrosis processes. We used antisense oligonucleotides for efficient downregulation of ncRNA LL35 (85-90\%) that was confirmed 
by qPCR and FISH techniques. Proteome of the cells with the inhibition ncRNA LL35 showed changes in the proteins connected with mitochondria and lipid metabolism, which can be explained by interaction of ncRNA LL35 with transcriptional coactivator PGC-1a.

This work is supported by the Russian Science Foundation under grant 177410140.

61

\section{THE SEARCH FOR BIOMARKERS OF MANGANESE DEFICIENCY}

Skalnaya Margarita G.

First Moscow State Medical University (Sechenov University), Moscow, Russia

RUDN University, Moscow, Russia

skalnaya@yandex.ru

Manganese (Mn) deficiency and intoxication are both associated with adverse metabolic effects. Therefore, monitoring of Mn exposure using specific and non-specific biomarkers is of particular interest. A total of 1318 women, 915 men, and 466 children were enrolled in the present study. Serum and urine Mn concentration was assessed using ICP-MS at NexION 300D (PerkinElmer, USA). Routine biochemical parameters and amino acid concentration were also studied. Results. Increased body mass index (BMI) was associated with significantly reduced serum Mn levels in 35-54 y.o. adults. Fasting plasma glucose in women with normal and high serum Mn levels is 3\% and 4\% higher as compared to low-Mn group ( ${ }^{\mathrm{KW}} \mathrm{p}=0.033$ ), whereas CRP levels are more than 2-fold lower in normal and high serum Mn groups ( $\left.{ }^{\mathrm{KW}} \mathrm{p}=0.023\right)$. Serum uric acid levels in high-Mn group exceed those in the low-Mn group by 22\% (237 vs 194), whereas Mn-associated increase in serum citrulline levels was only border-line significant. Both glutamine and ornithine levels were characterized by a significant 9\% decrease in high-Mn group as compared to the low-Mn, whereas the trend to Mn-associated decrease is significant for glutamine ( $\left.{ }^{\mathrm{KW}} \mathrm{p}=0.037\right)$. Generally, it is proposed that serum Mn concentration as well as the levels of Citrulline, Ornithine, Glutamine and Arginine being involved in ammonia metabolism could be considered as possible biomarkers of Mn deficiency and/or excess in humans.

\section{2}

\section{TRACE ELEMENTS IN NEURODEVELOPMENTAL DISORDERS}

Skalny Anatoly V., MD, PhD, DSc, Prof

IM Sechenov First Moscow State Medical University, Moscow, Russia

RUDN University, Moscow, Russia

skalny3@microelements.ru

Micronutrients and especially essential trace elements play a significant role in brain development, whereas alteration of their handling (both excess and deficiency) is associated with neurodevelopmental disorders. Moreover, exposure to heavy metals may also interfere with essential metal metabolism and its role in neurodevelopment. Therefore, the objective of a series of studies was to investigate both essential and toxic trace element levels in biosamples of children with neurodevelopmental disorders (autism spectrum disorder, attention-deficit hyperactivity disorder, cerebral palsy). Our recent data demonstrate that hair and urinary selenium levels were found to be increased in communication disorders, ASD and to a lesser extent in ADHD, whereas serum Se concentration tended to decrease in neurodevelopmental disorders. An inverse association between serum Se and heavy metal $(\mathrm{Pb}, \mathrm{Hg})$ levels was observed in patients with ASD. Taken together, these findings are indicative of increased selenium loss and selenium deficiency in children with the studied disorders that may be at least partially associated with toxic metal overload. Moreover, serum levels of certain essential elements $(\mathrm{Mg}, \mathrm{V}, \mathrm{Se}, \mathrm{Cr}$ ) were also associated with markers of neuroinflammation. In addition, alteration of trace element metabolism was shown to be associated with particular symptoms and syndromes of neurodevelopmental disorders. It is proposed that essential micronutrients $(\mathrm{Zn}, \mathrm{Se}, \mathrm{Mg}$ ) may posses neuroprotective effect through their antioxidant, anti-inflammatory, and detoxicative activity, thus being a potent target and tool for nutritional management of neurodevelopmental disorders. 


\section{3 \\ MUTATION VARIABILITY OF THE TR53 GENE FOR RENAL CELL CARCINOMA USING HRM (HIGH RESOLUTION MELT ANALYSIS)}

Smirnova E.G. ${ }^{1}$, Kipen V.N. ${ }^{2}$, Melnov S.B. ${ }^{2}$, Mohort A.A. ${ }^{3}$

${ }^{1}$ International Sakharov Environmental Institute of Belarusian State University, Minsk, Belarus

${ }^{2}$ The Institute of Genetics and Cytology of The National Academy of Sciences of Belarus, Minsk, Belarus

${ }^{3} \mathrm{~N}$. N. Alexandrov National Cancer Centre of Belarus, Lesnoy, Minsk Disrtict, Minsk Region, Belarus

e.smirnova@tut.by

Background and Objectives. In the world every year, more than $200 \mathrm{~K}$ people become ill with renal cell carcinoma (RCC). RCC - heterogeneous group of malignant tumors: 75-80\% of which are clear cell renal cell carcinoma (CCRCC); 5-10\% are papillary carcinomas; 5\% - chromophobic carcinoma and the remaining 5\% are represented by rare forms - carcinoma of the collecting ducts, oncocytoma, etc. [Mikhailenko D.S. et al., Oncourology, 2010, No. 2, pp. 32-36].

Over the past 10 years, studies in the field of molecular biology of carcinogenesis have accumulated a large number of data on the mechanisms of RCC development (primarily CCRCC). The TP53 gene (tumor protein p53, NCBI Gene ID: 7157) is inactivated in CCRCC due to somatic mutations, loss of heterozygosity and/or methylation. Missense mutations or deletions/inversions that lead to a shift in the reading of genetic information in the TP53 gene lead to the loss of its functional activity. The spectrum of these mutations is very wide - now more than 200 changes in the primary gene sequence are annotated (http://p53.iarc.fr/).

Methods. The most acceptable from the standpoint of "cost/time" scheme for the analysis of mutations in the TP53 gene in RCC is the scheme of research using SSCP (Single-strand conformation polymorphism) or more accurate Real-time PCR with analysis of melting curves (HRM, High Resolution Melting).

We tested at the instrument Bio-Rad CFX96 Touch (Bio-Rad) five pairs of primers: for exon 5 (F15'-GCCCTGACTTTCAACTCTGTCT-3', R1 5'-ACAGCTGCACAGGGCAGGTCTT-3'; F2, 5'-TGCCCTCAACAAGATGTTT-3' and R2 5'-CACAACCTCCGTCATGTG-3'; F3, 5'-GGCCATCTACAAGCAGTCA-3', R3: 5'-CAACCAGCCCTGTCGTCT-3') for exon 7 (F 5'-ACTGGCCTCATCTTGGGCCT-3', R 5'-TGTGCAGGGTGGCAAGTGGC-3') and for exon 8 (F 5'-TAAATGGGACAGGTAGGACC-3', R 5'-TCCACCGCTTCTTGTCCTGC-3') of the TP53 gene. PCR samples we are examined for tumor tissue RCC provided by State Institution "N.N. Alexandrov National Cancer Centre of Belarus" from patients with clinically verified diagnosis. The size of the analyzed amplicons was in the range of 100-230 p. o. The clustering results we are analyzed using the software Bio-Rad Precision Melt Analysis (Bio-Rad, USA). The accuracy of differentiation with the most conservative parameters of the analysis was not less than $95 \%$.

Results. As a result, the total frequency of minor clusters for 5 exon of TP53 gene among patients with RCC was 28.6\% (24/84), for 7 exon - 20.3\% (14/69), for 8 exon - 4.2\% (3/71) - figure 1.

Our results are consistent with those previously described by Aidan P. Nom et al. data (p53 and MDM2 in Renal Cell Carcinoma / Cancer. 2013. Vol. 116(4). pp.780-790.). However, as a rule, the results for HRM analysis are somewhat overstated compared to the sequencing data.

Conclusions. In this regard, further research suggests sequencing 5, 7 and 8 exons for those samples that have been differentiated by Bio-Rad Precision Melt Analysis as containing mutations.
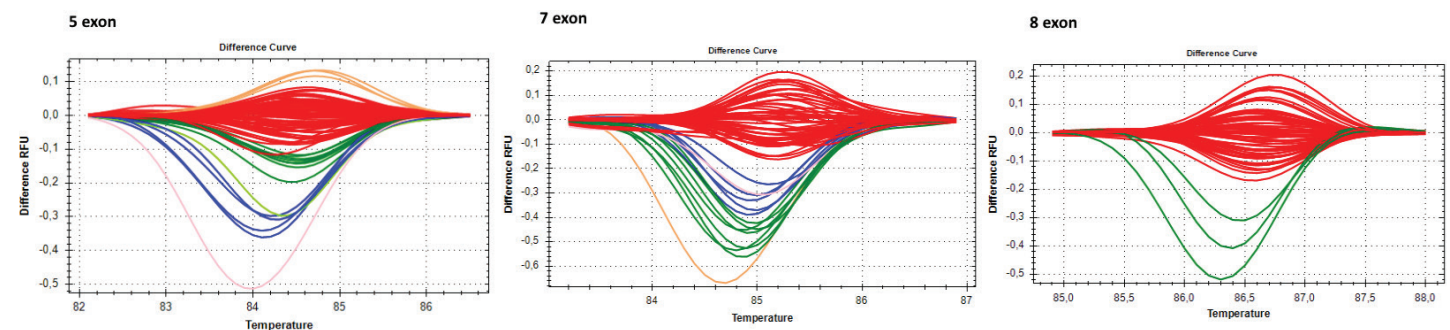

Fig. 1. The clustering results using the software Bio-Rad Precision Melt Analysis (Bio-Rad, USA). 
64

\title{
PATIENT-SPECIFIC TREATMENT OF HEREDITARY MUSCULAR ATROPHIES
} AND DYSTROPHIES IN CHILDREN

\author{
Sokolova M.G. ${ }^{1}$, Lopatina E.V. ${ }^{2}$, A.V. Kipenko ${ }^{2}$ \\ ${ }^{1}$ North-West State Medical University namen after I.I. Mechnikov, \\ ${ }^{2}$ Pavlov First Saint-Petersburg State Medical University namen after I.P. Pavlov, Saint-Petersburg, Russia \\ sokolova.m08@mail.ru
}

Hereditary neuromuscular diseases are a group of genetic diseases characterized by early onset, in most cases in childhood, with a steadily progressive course of the pathological process, leading to accelerated disability onset in patients and high mortality rate at the age of 18-20 years. Now these diseases are still incurable, and application of traditional approaches aimed at intensification of reparative and protective processes in the nervous tissue, unfortunately, is not scientifically justified. In our opinion, death of a large population of neurons in children with these diseases, due to genetic defects, creates a specific intraorgan environment due to activation of anti-apoptotic regulatory peptides, which also include neurotrophic factors. These features, of course, must be considered when treating patients with hereditary neuromuscular diseases.

Study objective. To study features of neurotrophic regulation in patients with hereditary muscular atrophies and dystrophies as a part of the clinical, laboratory and experimental study in order to develop principles of patient-specific symptomatic therapy.

Materials and methods. We have examined 90 patients with hereditary neuromuscular diseases (spinal muscular atrophies of types 1,2 and $3(n=30)$, Duchenne's muscular dystrophy $(n=60)$ ); control group: 30 healthy people. In vitro: sensory ganglia explants of 10-12-day chicken embryos.

We have carried out comprehensive clinical, laboratory, instrumental and experimental research. Concentration of neurotrophic factors (BDNF, NGF, CNTF) was determined by ELISA in blood plasma samples using kits by RayBiotech, Inc and in accordance with the manufacturer's instructions. Electroneuromyography was performed using Pegasus computer myography system by Nicolet (USA). Microscopic analyses of the explants were performed using the equipment of the Confocal Microscopy Core Facilities Centre of Pavlov Institute of Physiology, RAS. For the purpose of visualization of the objects we used Axiostar Plus microscope (Carl Zeiss, Germany). The images obtained were analyzed using ImageJ software. Statistical analysis was performed using STATISTICA 8.0 package (StatSoft ${ }^{\circ}$, Inc., USA, 2012).

Results of the study. The conducted studies helped us to identify some features of neurotrophic regulation in patients with hereditary neuromuscular diseases, which are important for their symptomatic therapy. For the first time we have registered elevated levels of NGF and BDNF neurotrophins in blood plasma of patients with motor neuron defects in patients with spinal muscular atrophy and a decrease in BDNF in patients with musculoskeletal system affection in patients with Duchenne's muscular dystrophy. In the series of experiments in conditions of organotypic culturing of spinal ganglia of 10-12-day chicken embryos in the presence of the blood plasma of patients with hereditary neuromuscular diseases, it was found that addition of synthetic nerve growth factor stimulates growth of neurites in the samples containing blood plasma of patients with Duchenne's muscular dystrophy and has the opposite effect on samples containing plasma of patients with spinal muscular atrophy, i.e. blood plasma has a neurite inhibitory effect. Statistical study showed a correlation between neurotrophins concentration level (NGF and BDNF) and blood plasma effect on the growth of neurites ( $\mathrm{p}<0.001)$.

Conclusion. The data obtained show that there are features of neurotrophic regulation in patients with hereditary muscular atrophies and dystrophies, which must be considered at symptomatic treatment aimed at stimulation of reparative processes in the nervous tissue. Patients with neurite-impaired plasma action should be treated with neuroprotective medicines, while medicines for patients with neurite-inhibitory effect on neurites in the organotypic culture of the nerve tissue should be individually selected in in vitro conditions using pharmacological analysis. The developed approach helps us to reduce economic costs of treatment of each patient, since it will shorten time for selection of correct patient-specific pharmacotherapy. 


\section{5 \\ MOLECULAR MECHANISMS INVOLVING CHROMIUM, VANADIUM, AND ZINC DYSHOMEOSTASIS IN METABOLIC SYNDROME}

Tinkov Alexey A., MD, PhD

Yaroslavl State University, Yarosvlavl, Russia

IM Sechenov First Moscow State Medical University, Moscow, Russia

RUDN University, Moscow, Russia

tinkov.a.a@gmail.com

Zinc (Zn), chromium (Cr), and vanadium (V) are essential trace elements playing a significant role in carbohydrate and lipid metabolism, although clinical data are scarce. Our recent examination of obese patients revealed reduced serum and elevated hair $\mathrm{Cr}$ and $\mathrm{V}$ levels as compared to the controls. Urinary $\mathrm{V}$ excretion was also increased, whereas hair Zn was lower in obese patients. In multiple regression models hair $\mathrm{Zn}$, as well as serum $\mathrm{Cr}$ and V levels were inversely associated with BMI. Analysis of serum trace element levels in patients with prediabetes and diabetes demonstrated that $\mathrm{Zn}$ levels were independently associated with glycemic control markers and the rate of insulin resistance (HOMA-IR). Experimental studies demonstrated that high caloric feeding in rats resulted in a significant decrease in adipose tissue $\mathrm{Zn}, \mathrm{Cr}$, and V content. The latter was also shown to be associated with adipocyte morphometry, adipokine spectrum (leptin, adiponectin), insulin resistance, and proinflammatory milieu (IL-6, MCP-1, TNF $\alpha$ ). Moreover, depression in adipose tissue trace element levels preceded alteration of metabolic parameters, being indicative of a significant contribution of $\mathrm{Zn}, \mathrm{Cr}$, and $\mathrm{V}$ dyshomeostasis in metabolic syndrome. The potential mechanisms of this association are discussed. Therefore, $\mathrm{Zn}, \mathrm{Cr}$, and $\mathrm{V}$ metabolism may be considered as both a marker and a target for correction of metabolic disturbances in obesity.

\section{6}

\section{MICROGLIAL DYSTROPHY IN THE PREFRONTAL CORTEX IN SCHIZOPHRENIA}

Uranova N.A.*, Vikhreva O.V.

Laboratory of Clinical Neuropathology, Mental Health Research Centre, Moscow, Russia

uranovan@mail.ru

Background and Objectives. Schizophrenia is a chronic progressive mental disorder accompanied by cognitive dysfunction, negative and positive symptoms. A growing evidence coming from clinical and neuroimaging studies demonstrated the impact of inflammation in the onset and progression of schizophrenia. Post-mortem studies showed increased or unchanged density of microglia in the prefrontal cortex, hippocampus and degeneration of microglia in the neocortex in schizophrenia. We aimed to perform a pilot postmortem morphometric study of the ultrastructure of microglia in the prefrontal cortex in schizophrenia $(\mathrm{n}=14)$ and healthy matched control $(\mathrm{n}=14)$ subjects.

Methods. Transmission electron microscopy and morphometry were applied to estimate the ultrastructural parameters of microglia in layer $\mathrm{V}$ of the prefrontal cortex (BA 10). The effects of diagnosis were analyzed using ANOVA-test. A Pearson correlation analysis was performed to assess correlations between the parameters and confounding variables.

Results. Area and cell density of microglial cells were not changed between the groups. The parameters of mitochondria (area, volume fraction, $\mathrm{Vv}$ and the number) were significantly decreased ( $\mathrm{p}<0.01$ ); $\mathrm{Vv}$ and the number of vacuoles and lipofuscin granules were significantly increased $(p<0.05)$ in the schizophrenia group as compared to the control group. These parameters were not correlated with age, post-mortem delay and neuroleptic exposure.

Conclusions. Our study provide for the first time evidence for dystrophy of microglia in schizophrenia as compared to controls. Abnormalities of mitochondria in microglia are the key alterations in schizophrenia. These abnormalities might be associated with oxidative stress. 


\section{WOULD MRI-IMAGING AFTER INTRAVENOUS INJECTIONS OF MAGNETITE NANOPARTICLES LOADED LIPOSOMES PREDICT EFFICIENCY OF FURTHER TREATMENT WITH LIPOSOMAL DRUGS?}

Vodopyanov Stepan ${ }^{1}$, Vlasova Ksenia ${ }^{2}$, Naumenko Viktor ${ }^{1}$, Garanina Anastasia ${ }^{1}$, Majouga Alexander ${ }^{2,3}$, Abakumov Maxim ${ }^{1,4}$

${ }^{1}$ NUST "MISIS", Moscow, Russia

${ }^{2}$ Lomonosov Moscow State University, faculty of chemistry, Moscow, Russia

${ }^{3}$ Dmitry Mendeleev University of Chemical Technology of Russia, Moscow, Russia

${ }^{4}$ Pirogov Russian National Research Medical University (RNRMU), Moscow, Russia

stepan.vodopianov@yandex.ru

The aim of our ongoing project is to test liposomes loaded with magnetite nanoparticles as MRI-contrast agents for personal prediction of potential efficiency of further anticancer treatment using liposomal forms of drugs. EPR-effect (enhanced permeability of tumor blood vessels and retention) is considered to be mechanism of drug delivery, but it may vary significantly among different tumor models and individually within groups. We checked 4 tumor models: 1) heterotopic 4T1, 2) orthotopic 4T1 (both on BALB/c mice), 3) orthotopic B16-F10 (on C57/bl mice) and 4) human prostate cancer 22rv1 cells as xenograph model on nude mice. Each animal had 2 contra-lateral tumors on back flanks. With MRI we evaluated the differences of tumors negative contrast after $1 \mathrm{~h}, 6 \mathrm{~h}, 24 \mathrm{~h}, 48 \mathrm{~h}$ post injection, the imaging before injection showed initial state to compare with. Each mice got about $4 \mathrm{mg} / \mathrm{kg}$ of ferrum. MRI revealed, that heterotopic 4T1 tumors accumulate negative contrast signal better than other studied models. About half of these tumors showed accumulation after $6 \mathrm{~h}$ post injection. 4T1 tumors often had tree-like structure of negative contrast signal, and B16-F10 and 22rv1 had spot-like pattern. We chose heterotopic 4T1 tumors as a model for treatment experiment on the next step.

The work was supported by the Ministry of Education and Science of the Russian Federation, program "Research and development in priority areas of scientific and technological complex of Russia for 2014-2020", agreement from 27.09.2017. №14.575.21.0147, RFMEFI57517X0147. 